\title{
What do primary care staff know and do about blood borne virus testing and care for migrant patients? A national survey
}

Rachel Roche ${ }^{1,2^{*}}$ (D), Ruth Simmons ${ }^{1,2}$, Alison F. Crawshaw ${ }^{3,4}$, Pip Fisher ${ }^{5}$, Manish Pareek ${ }^{6}$, Will Morton? Theresa Shryane ${ }^{8}$, Kristina Poole ${ }^{8}$, Arpana Verma ${ }^{5}$, Ines Campos-Matos ${ }^{3,9}$ and Sema Mandal ${ }^{1,2}$

\begin{abstract}
Background: UK migrants born in intermediate to high prevalence areas for blood borne viruses (BBV) including hepatitis B, hepatitis C and HIV are at increased risk of these infections. National guidance from Public Health England (PHE) and National Institute for Health and Care Excellence (NICE) recommends primary care test this population to increase diagnoses and treatment. We aimed to investigate primary care professionals' knowledge of entitlements, and perceptions of barriers, for migrants accessing healthcare, and their policies, and reported practices and influences on provision of BBV testing in migrants.

Methods: A pre-piloted questionnaire was distributed between October 2017 and January 2018 to primary care professionals attending the Royal College of General Practitioners and Best Practice in Primary Care conferences, via a link in PHE Vaccine Updates and through professional networks.

Survey results were analysed to give descriptive statistics, and responses by respondent characteristics: profession, region, practice size, and frequency of seeing migrant patients. Responses were considered on a per question basis with response rates for each question presented with the results.

Results: Four hundred fourteen questionnaires were returned with responses varying by question, representing an estimated $5.7 \%$ of English GP practices overall. Only 14\% of respondents' practices systematically identified migrant patients for testing. Universal opt-out testing was offered to newly registering migrant patients by $18 \%$ of respondents for hepatitis B, 17\% for hepatitis C and 21\% for HIV. Knowledge of healthcare entitlements varied; fewer clinical staff knew that general practice consultations were free to all migrants (76\%) than for urgent care (88\%). Performance payment structure (76\%) had the greatest reported influence on testing, followed by PHE and Clinical Commissioning Group recommendations (73\% each). Language and culture were perceived to be the biggest barriers to accessing care.

(Continued on next page)
\end{abstract}

\footnotetext{
* Correspondence: rachel.roche@phe.gov.uk

${ }^{1}$ Blood Safety, Hepatitis, Sexually Transmitted Infections (STI) and HIV Service, National Infection Service, Public Health England, 61 Colindale Avenue, London NW9 5EQ, UK

${ }^{2}$ The National Institute for Health Research Health Protection Research Unit (NIHR HPRU) in Blood Borne and Sexually Transmitted Infections at University College London, Gower St, London WC1E 6BT, UK

Full list of author information is available at the end of the article
}

C C The Author(s). 2021 Open Access This article is licensed under a Creative Commons Attribution 4.0 International License, which permits use, sharing, adaptation, distribution and reproduction in any medium or format, as long as you give appropriate credit to the original author(s) and the source, provide a link to the Creative Commons licence, and indicate if changes were made. The images or other third party material in this article are included in the article's Creative Commons licence, unless indicated otherwise in a credit line to the material. If material is not included in the article's Creative Commons licence and your intended use is not permitted by statutory regulation or exceeds the permitted use, you will need to obtain permission directly from the copyright holder. To view a copy of this licence, visit http://creativecommons.org/licenses/by/4.0/. The Creative Commons Public Domain Dedication waiver (http://creativecommons.org/publicdomain/zero/1.0/) applies to the data made available in this article, unless otherwise stated in a credit line to the data. 
(Continued from previous page)

Conclusions: BBV testing for migrant patients in primary care is usually ad hoc, which is likely to lead to testing opportunities being missed. Knowledge of migrants' entitlements to healthcare varies and could affect access to care. Interventions to improve professional awareness and identification of migrant patients requiring BBV testing are needed to reduce the undiagnosed and untreated burden of BBVs in this vulnerable population.

Keywords: Hepatitis B, Hepatitis C, HIV, Blood borne virus, Testing, Screening, General practice, Migrants, Healthcare access, UK

\section{Background}

Migrants in the UK from intermediate or high prevalence areas for HIV, hepatitis $\mathrm{B}(\mathrm{HBV})$ and hepatitis $\mathrm{C}$ $(\mathrm{HCV})$ are at increased risk of these infections compared to the UK-born population, and experience a disproportionate burden of disease [1-3]. In 2017 almost half (49\%) of newly diagnosed cases of HIV among heterosexuals were among black Africans or heterosexuals born in a high prevalence country [2] and an estimated 95\% of new chronic HBV infections in the UK are among individuals who probably acquired their infection overseas in endemic countries, often perinatally or in childhood [4]. For all three blood borne viruses (BBV) the undiagnosed fraction remains high, with a high proportion of infections diagnosed late, potentially contributing to avoidable morbidity and mortality and increased risk of onward transmission [5-8].

In 2016, the UK government signed up to the World Health Organisation (WHO) goal of eliminating viral hepatitis as a public health threat by 2030 [9]. HBV and $\mathrm{HCV}$ testing in primary care for migrants from countries with intermediate or high prevalence $(>2 \%)$ has been recommended by National Institute for Health and Care Excellence (NICE) guidance since 2012 [10], and since 2018 European Centre for Disease Prevention and Control (ECDC) recommends screening newly arrived migrants for BBV [11]. Although surveillance data indicates that an increasing proportion of BBV diagnoses take place in primary care, evidence suggests a low proportion of eligible migrants receive the recommended BBV testing in this setting $[12,13]$.

Language, stigma and poor knowledge and understanding of disease create barriers for migrants to accessing testing and treatment for viral hepatitis [14, 15] and migrants often experience discrimination and bureaucratic obstacles when trying to access healthcare [16, 17]. In August 2017 UK healthcare entitlements for migrants changed and the list of chargeable services was expanded [18, 19]. While many services, including primary care, are still free to all migrants, for others a patient should now be deemed ordinarily resident in the UK to access services for free. Sexual health, family planning, GP and nurse consultations in primary care, emergency department (ED) and walk-in centres, and treatment of mental and physical conditions caused by torture, female genital mutilation (FGM), domestic or sexual violence are free to all migrants, while communicable disease diagnosis and treatment is free to all for a list of specified diseases, including HIV, viral hepatitis, TB and Middle East respiratory syndrome [18-20]. For surgery or outpatient services in secondary care, a patient should be deemed ordinarily resident in the UK to access the service free of charge. This additional complexity may lead to uncertainty among both migrants and professionals about entitlements, and could create additional barriers to accessing services.

We, therefore, conducted a national survey to understand primary care staff's knowledge, attitudes, policies and practice regarding BBVs in migrant patients, influences on these, and their perceptions of the barriers for migrants in accessing healthcare.

\section{Methods}

Study design

A cross-sectional survey conducted among primary care staff in England.

\section{Study population}

The target population for this study were primary care staff working in general practices in England. All primary care staff were eligible for inclusion, but it was expected that respondents would primarily be general practitioners (GPs) and practice nurses.

\section{Sampling procedures}

A convenience sampling approach was used, with survey participants recruited through several routes during October 2017. Firstly, the link to the online survey was circulated via primary care networks of local Public Health England (PHE) Health Protection Teams across England. Secondly, the link to the online survey was circulated in the PHE publication Vaccine Updates, a newsletter primarily subscribed to by general practice professionals with distribution $\sim 46,000$. These two routes were used opportunistically and in parallel in order to access primary care professionals, as we did not have access to another primary care network with equivalent coverage across England. 
In addition, stalls were held at the Royal College of General Practitioners (RCGP) annual conference in Liverpool and the Best Practice in Primary Care conference in Birmingham, both in October 2017. Attendees were approached and asked to participate in the survey via tablet devices, or offered shorter paper versions of the survey to take away and return once completed.

Due to the timeframe and budget of the project, participants were not followed up to respond to the survey, and the online survey was closed in January 2018.

\section{Data collection}

The survey was created as an online questionnaire using SelectSurvey.net ${ }^{\mathrm{tw}}$ software (ClassApps LLC, Kansas City, Missouri) and responses were exported into Excel for analysis. Shorter paper versions of the survey were also distributed among participants attending the two primary care conferences. Responses from paper surveys were manually input into Excel by the lead author.

\section{Questionnaire design}

The questionnaire was developed at PHE in collaboration with a project group of clinicians, academic GPs and qualitative researchers and piloted before launch with a group of 4 academic GPs.

The questionnaire consisted of 37 questions covering the following topics.

1. Respondent and practice characteristics

2. Clinical questions analysed for clinical staff (GPs and nurses) only: Knowledge of migrants' entitlements to health services; Issues considered for newly registering migrant patients; Knowledge of testing serology; Management of patients diagnosed with hepatitis B and C; Incentives / motivation for BBV testing

3. Practice policy questions analysed for all respondents: Practice policy for offering BBV testing to migrants; Identification of migrants for BBV testing; Recording of routine data

4. Barriers questions analysed for all respondents: Perceived barriers for migrants to accessing healthcare across the care pathway: Healthcare; BBV testing in primary care; Secondary care for patients with BBV; Barriers for asylum seekers

The full questionnaire took approximately $17 \mathrm{~min}$ to complete (see additional file 1 for full online questionnaire and additional file 2 for shorter paper questionnaire). Most questions were multiple choice, apart from those relating to barriers, practice size and practice population which were free text.

To investigate knowledge of healthcare entitlements respondents were asked, as of August 2017, which services were free irrespective of migration status, using legislation and implementation guidelines to define correct responses $[18,19]$.

Respondents were asked about location of practice and professional role. No additional respondent characteristics were sought as the focus of the survey was on practice, not individual characteristics.

\section{Definitions}

A migrant is defined as someone who changes their country of usual residence, in whatever manner, for whatever reason and irrespective of their legal status. The UN defines a permanent migrant as someone who moves to a country for a period of 12 or more months, often for work, education or joining family, effectively making it their new country of usual residence [21]. A refugee is defined as someone who has fled their home country for reasons of feared persecution, conflict, generalised violence or other circumstances that have seriously disturbed public order and are seeking protection in another country [21]. In the UK, for a person to be officially recognised as a refugee they first have to make a claim for asylum and have this accepted by the government. An asylum seeker is a person who seeks safety from persecution or serious harm in a country other than their own and has formally applied for asylum (i.e. refugee status) from that country, but is awaiting a decision on their application [22].

A definitions sheet was provided with the survey to help respondents understand terms relating to migration which also included refused asylum seeker and undocumented migrant (not specifically mentioned in the questionnaire) (additional file 3).

Definitions of other terms used are as follows: Clinical staff: respondents who identified their role as either GP (GP partner, Salaried GP, Locum GP, or 'other' and specified GP), or nurse (Practice Nurse or 'other' and specified nurse). In questions relating to practice policy for $\mathrm{BBV}$ testing, new migrants refer to newly registering patients who were migrants from outside the UK (regardless of when they had migrated), and existing migrants refer to patients already registered with the practice who had ever migrated from outside the UK. When asking about practice characteristics, the proportion of new migrants on a practice list was defined as migrants registered with the practice who had lived in the UK for 5 years or less, regardless of when they registered.

The roles of GPs and nurses in the diagnosis and management of BBVs vary by practice. Practice nurses undertake a range of nursing assessments and provide appropriate care / treatment in conjunction with GPs according to practice policy and protocols and are likely to be responsible for vaccination and testing, whereas GPs 
would usually be responsible for clinical diagnoses and referrals to secondary care.

Practice size was defined as small, medium or large using tertiles of practice populations in England reported by NHS Digital for December 2017 [23].

\section{Data analysis}

Results were collated and de-duplicated using email addresses. Practice names were checked to identify if there were multiple respondents from the same practice, but these were not de-duplicated as responses differed and were from different professionals.

Due to the methods used to circulate the survey via an e-bulletin to which practices subscribe, it was not possible to calculate a formal response rate. Instead, the number of responses as a proportion of GP practices in England (based on NHS data from 2017) was calculated to provide an indication of the proportion of England GP practices represented in responses [23].

Results were analysed in Excel and $\mathrm{R}$ for overall descriptive statistics (percentages and 95\% confidence intervals (CI)) and then stratified by respondent and practice characteristics. Responses for clinical knowledge and practice questions were restricted to those who gave their role as GP or nurse and stratified by profession. Responses for practice policy questions were analysed for all respondents, and stratified by region, frequency of seeing migrant patients, and practice size.

To assess the statistical significance of differences in responses to questions, and for differences by stratified analysis, variables were dichotomised where required before performing Chi squared tests. Where this was done, the dichotomous outcome is highlighted in bold in results tables. Fishers exact tests were used where the cross-tabulation did not meet the criteria for Chi squared tests. Differences were considered statistically significant where $p<0.05$.

Free text responses on barriers were grouped by thematic analysis into 10 themes: language/culture, patient information/knowledge, staff information/knowledge, psychological, accommodation, prejudice/discrimination, patient financial, organisational resource, geographical, and service/organisational issues.

Each question had a different response rate, and descriptive statistics were based on the number of respondents for each question, which are presented with the results.

\section{Results}

\section{Respondent and practice characteristics}

The survey was circulated through the PHE Vaccine Updates circulation list, although it is not known how many will have actively read this, and others may have been forwarded the survey link by contacts. After deduplication 414 responses were obtained; 16 paper and 398 online, an estimated 5.7\% response rate, based on the number of GP practices in England. The majority of responses came from circulation of the survey link as response at conferences was poor; no attendees completed the online survey on the day, and only 16 paper surveys were returned. Where practice name was reported (145 respondents), there were 3 practices that each had 2 respondents, all other practices were unique. Most respondents were practice nurses (49\%, 202/414) and GPs $(40 \%, 165 / 414)$ with the highest responses from the Midlands $(21 \%, 86 / 414)$, the South East $(16 \%, 65 /$ 414) and London (15\%, 63/414) (Table 1). Responses were equally distributed among those who reported they saw migrant patients frequently $(34 \%, 108 / 317)$, sometimes $(33 \%, 103 / 317)$ and rarely $(33 \%, 106 / 317)(77 \%$ response rate).

Practice characteristics were poorly completed; only $151(38 \%)$ respondents reported their practice size and of these $26 \%$ (39/151) were small $(<5280$ patients), $28 \%$ (42/151) were medium (5280-9300 patients) and 46\% $(70 / 151)$ were large ( $>=9300$ patients). Of the $79(20 \%)$ respondents who reported the proportion of new migrants $(<5$ years in the UK) on their practice list, $50 \%$ (40/79) had < 10, 32\% (25/79) had 10-24\% and 13\% (10/ $79)$ had over $50 \%$. Similarly, of the 75 (19\%) who reported the proportion of their practice list that were asylum seekers/refugees, 76\% (57/75) had < 10, 9\% (7/75) had $10-24 \%$ and only $11 \%(8 / 75)$ had over $50 \%$. There were no significant differences in practice or other respondent characteristics by professional role $(p>0.2)$.

\section{Professional knowledge and practice} Issues considered for newly registering patients who are migrants

When asked which issues were always addressed for newly registering patients who are migrants (response rate $78 \%$ of GPs and nurses), vaccination history was the most common always addressed issue $(58.2 \%, 167 / 287$, 95\% CI 52.4-63.7), and family planning, TB screening, sexual health and BBV screening more often considered on a situation-specific basis (Table 2). The proportion that never addressed issues ranged from 4.9\% (14/287, 2.9-8.0) for vaccination history and family planning to $11.8 \%(34 / 287,8.6-16.1)$ for TB screening. BBV risk assessments were considered for all newly registering migrant patients by $29.6 \%(85 / 287,24.6-35.1), 27.2 \%(78 /$ $287,22.4-32.6)$ and $30.0 \%(86 / 287,25.0-35.5)$ for HBV, $\mathrm{HCV}$ and HIV respectively and this did not differ by the respondent's profession $(p=0.763, p=0.953$ and $p=$ 0.867 respectively). TB screening was addressed for all newly registering migrant patients by $28.6 \%(82 / 287$, 23.7-34.1) of respondents, and this did not differ by profession $(p=0.072)$. There were significant differences in 
Table 1 Respondent and practice characteristics

\begin{tabular}{|c|c|c|c|}
\hline & & Overall & \\
\hline & & Number (\%) & $95 \% \mathrm{Cl}$ \\
\hline 1a: Respondent characteristics & & & \\
\hline Position & General Practitioner (GP) & $165(39.9)$ & $35.3-44.6$ \\
\hline & Nurse & $202(48.8)$ & 44.0-53.6 \\
\hline & Practice Manager & $29(7.0)$ & $4.9-9.9$ \\
\hline & Other clinical & $6(1.4)$ & $0.7-3.1$ \\
\hline & Other non-clinical & $7(1.7)$ & $0.8-3.4$ \\
\hline & Not stated & $5(1.2)$ & $0.5-2.8$ \\
\hline & Total responses & 414 & \\
\hline Frequency of seeing migrant patients & Frequently & $108(34.1)$ & $29.1-39.4$ \\
\hline & Sometimes & $103(32.5)$ & $27.6-37.8$ \\
\hline & Rarely & $106(33.4)$ & $28.5-38.8$ \\
\hline & Total responses & 317 & \\
\hline 1b: Practice characteristics & & & \\
\hline Location & East of England & $36(8.7)$ & $6.3-11.8$ \\
\hline & London & $63(15.2)$ & $12.1-19.0$ \\
\hline & Midlands & $86(20.8)$ & $17.1-24.9$ \\
\hline & North East & $23(5.6)$ & $3.7-8.2$ \\
\hline & North West & $60(14.5)$ & $11.4-18.2$ \\
\hline & South East & $65(15.7)$ & $12.5-19.5$ \\
\hline & South West & $30(7.2)$ & $5.1-10.2$ \\
\hline & Yorkshire \& the Humber & $51(12.3)$ & $9.5-15.8$ \\
\hline & Total responses & 414 & \\
\hline Size of practice & Small (0-5279 patients) & $39(25.8)$ & $19.5-33.3$ \\
\hline & Medium (5280-9299 patients) & $42(27.8)$ & $21.3-35.4$ \\
\hline & Large (> = 9300 patients) & $70(46.4)$ & $38.6-54.3$ \\
\hline & Total responses & 151 & \\
\hline Proportion of practice population that are new migrants & Low (0-9\%) & $40(50.6)$ & 39.8-61.4 \\
\hline & Medium (10-24\% patients) & $25(31.6)$ & $22.4-42.5$ \\
\hline & High (25-49\% patients) & $4(5.1)$ & $2.0-12.3$ \\
\hline & Very high (50-100\% patients) & $10(12.7)$ & $7.0-21.8$ \\
\hline & Total responses & 79 & \\
\hline Proportion of practice population that are asylum seekers/refugees & Low (0-9\%) & $57(76.0)$ & $65.2-84.2$ \\
\hline & Medium (10-24\% patients) & $7(9.3)$ & $4.6-18.0$ \\
\hline & High (25-49\% patients) & $3(4.0)$ & $1.4-11.1$ \\
\hline & Very high (50-100\% patients) & $8(10.7)$ & $5.5-19.7$ \\
\hline & Total responses & 75 & \\
\hline
\end{tabular}

practice by profession for vaccination history, family planning, and sexual health advice and screening (all $p<$ 0.01 ), with nurses more likely than GPs to address these issues for all newly registering migrant patients.

\section{Knowledge of migrants' entitlements to health services} When asked about migrants' entitlements to health services (100\% response rate), 88.3\% (323/366, 84.5-91.2) of clinical staff correctly identified emergency departments and walk-in centres as free to all and $76.0 \%$ (279/367, 71.4-80.1) correctly identified GP and nurse consultations in primary care as free to all, with no difference by profession ( $p=0.565$ and 0.262 respectively, Table 2). Surgery or outpatient services in secondary care were correctly identified as not free to all by $52.3 \%$ (192/367, 47.2-57.4), and this was higher for GPs $(59.4 \%, 98 / 165,51.8-66.6)$ than nurses $(46.5 \%, 94 / 202$, $39.8-53.4)(p=0.014)$. 


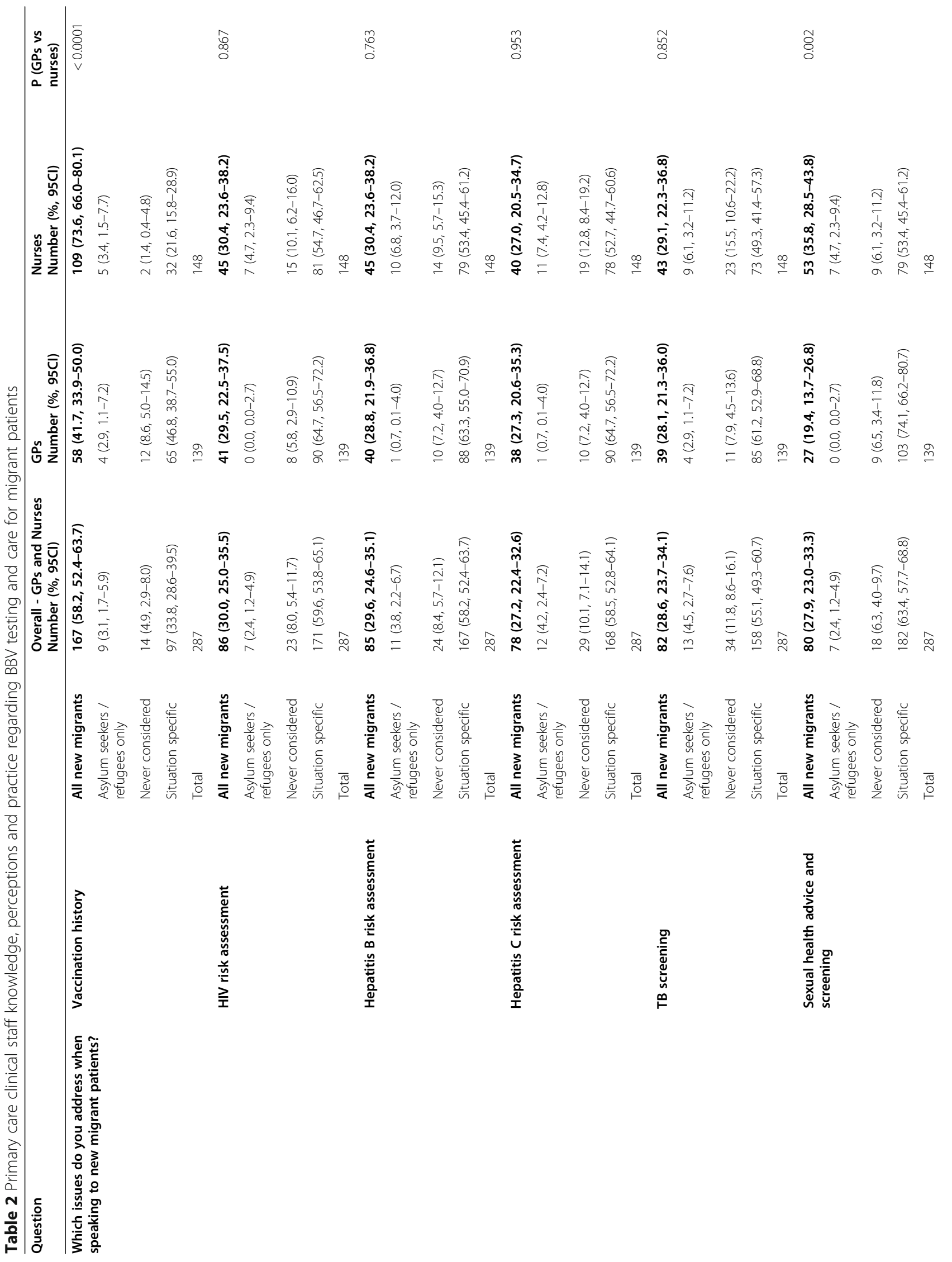




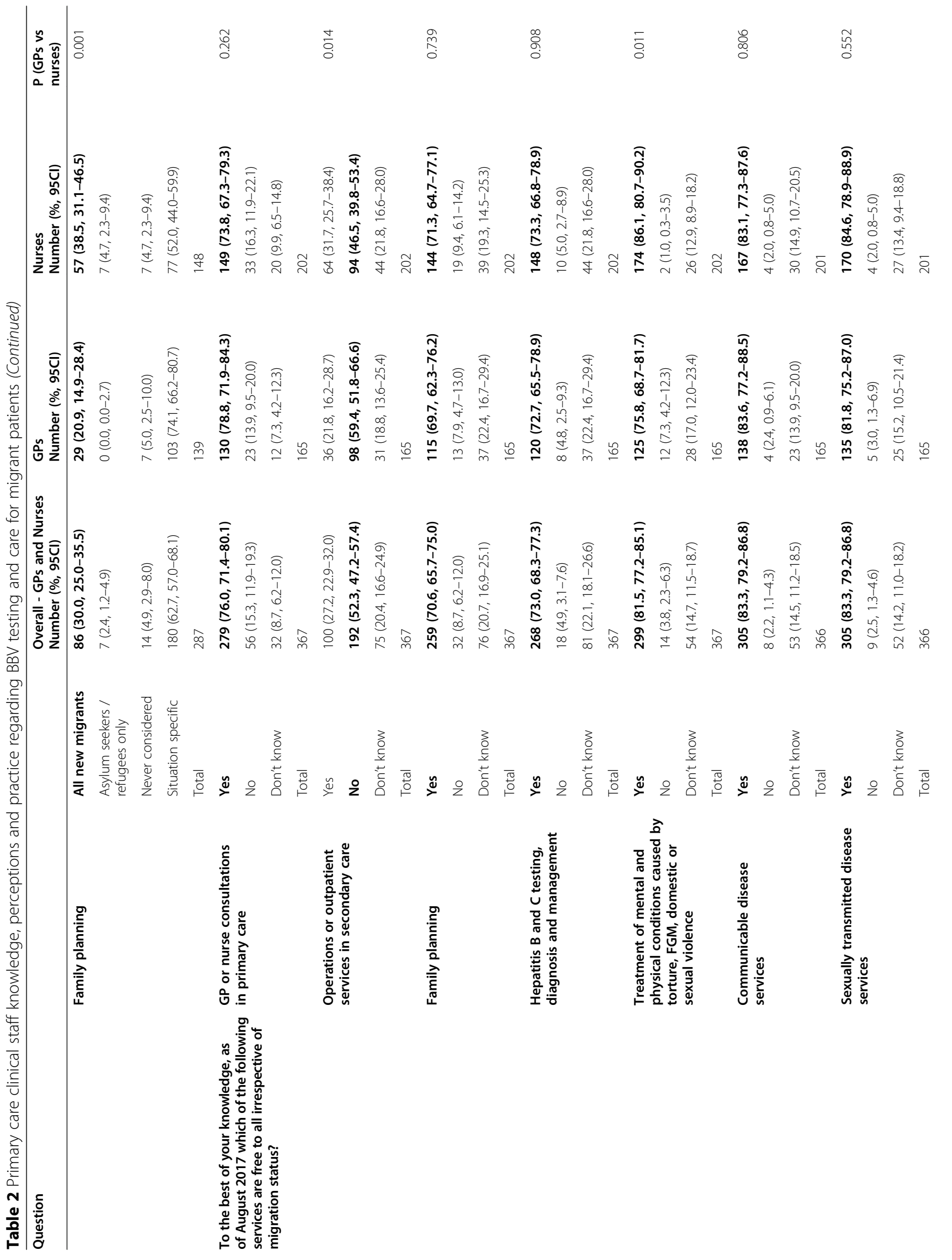




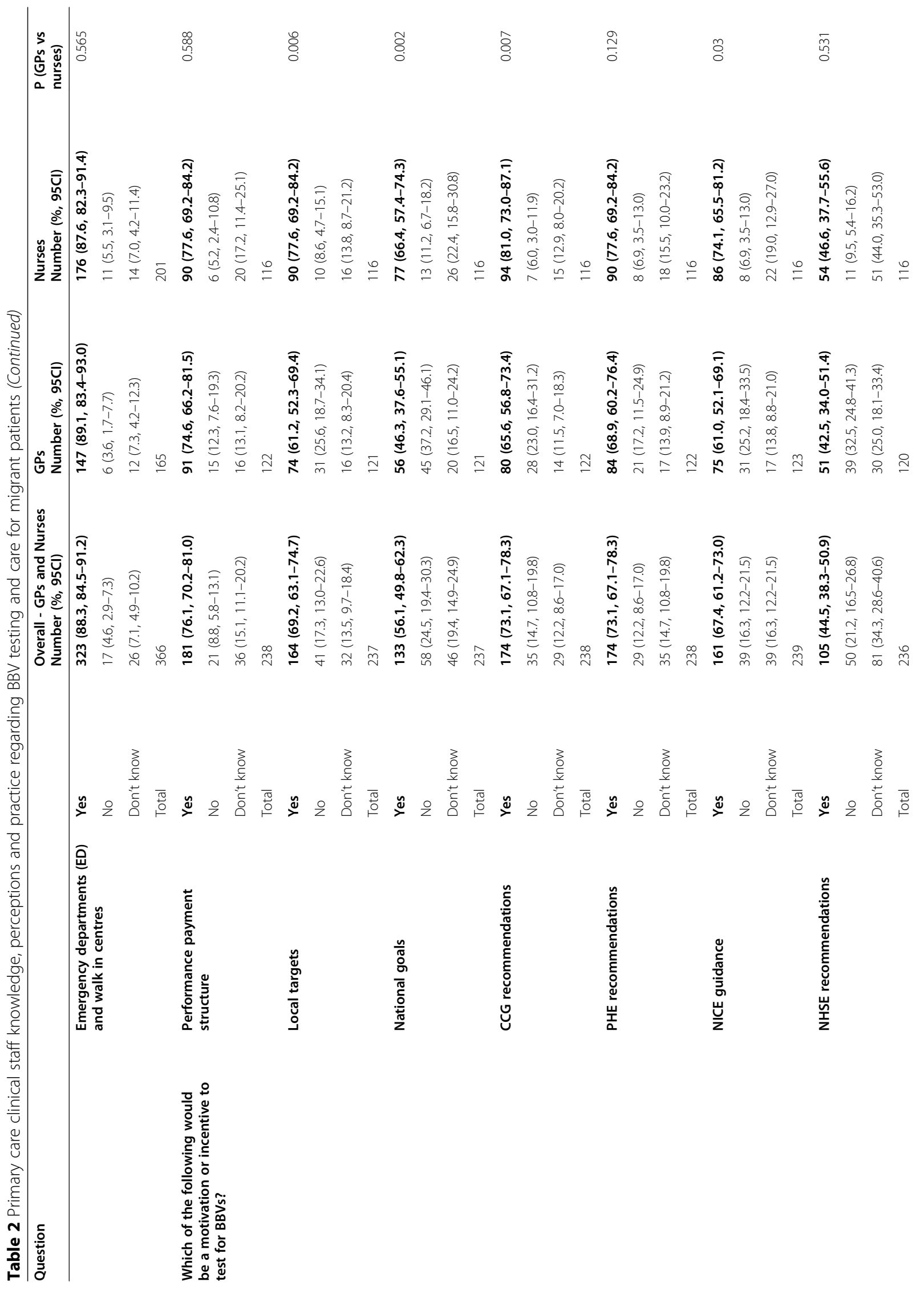




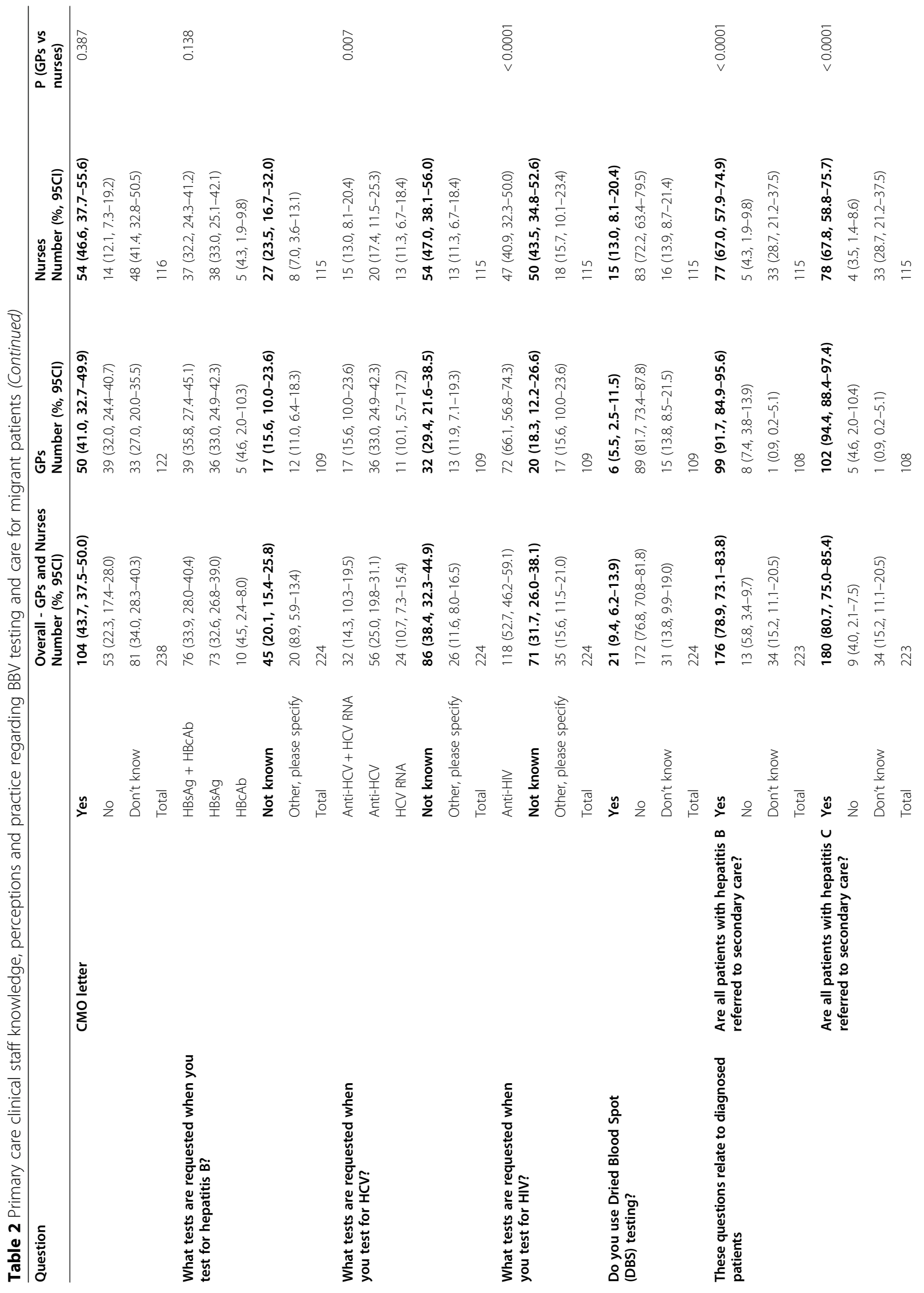




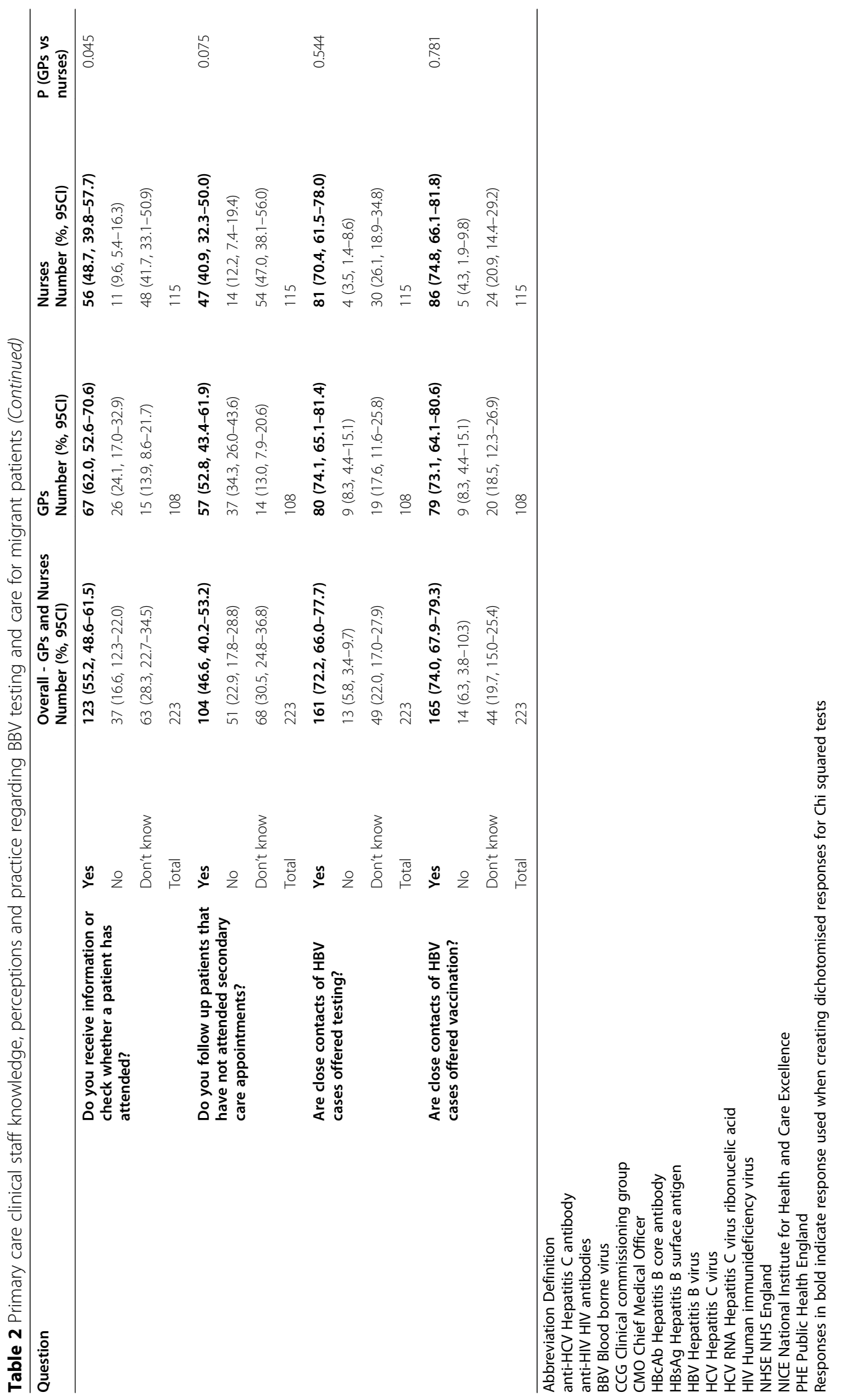




\section{Laboratory tests for BBV diagnosis}

When testing for HBV (64\% response rate), 32.6\% (73/ 224, 26.8-39.0) of clinical staff requested tests for hepatitis B surface antigen (HBsAg) only, 33.9\% (76/224, 28.0-40.4) requested both $\mathrm{HBsAg}$ and hepatitis B core antibody (HBcAb) testing, 4.5\% (10/224, 2.4-8.0) tested for HBcAb only, $20.1 \%(45 / 224,15.4-25.8)$ did not know what test was requested and $8.9 \%(20 / 224,5.9-13.4)$ stated 'other,' with most in this group stating that the laboratory determined the tests (Table 2). These results did not differ by profession $(p=0.138)$.

For HCV (64\% response rate), 33.0\% (36/109, 24.944.3) GPs and $17.4 \%(20 / 115,11.5-25.3)$ nurses tested for hepatitis C antibody (anti-HCV) only, 15.6\% (17/109, 10.0-23.6) GPs and $13.0 \%(15 / 115,8.1-20.4)$ nurses tested for both anti-HCV and HCV RNA, while $10.1 \%$ $(11 / 109,5.7-17.2)$ GPs and $11.3 \%(13 / 115,6.7-18.4)$ tested for HCV RNA only. There were $29.4 \%(32 / 109$, $21.6-38.5)$ of GPs and $47.0 \%(54 / 115,38.1-56.0)$ of nurses who did not know which tests were ordered $(p=$ $0.007)$, and $11.6 \%(26 / 224,8.0-16.5)$ stated 'other'; most of these stated that the laboratory determined the test, or that a tick-box 'hep C screen' was completed.

For HIV (64\% response rate), 66.1\% (72/109, 56.874.3) GPs and $40.9 \%(47 / 115,32.3-50.0)$ nurses tested for HIV antibodies, $18.3 \%(20 / 109,12.2-26.6)$ GPs and $43.5 \%(50 / 115,34.8-52.6)$ nurses did not know what tests were ordered, and $15.6 \%(35 / 224,11.5-21.0)$ stated 'other.' Significantly more nurses than GPs did not know which tests were required for diagnosis of HCV and HIV $(p<0.01)$.

\section{Incentives for testing}

Performance payment structure, PHE recommendations, Clinical Commissioning Group (CCG) recommendations, local targets, NICE recommendations and national goals were all endorsed as incentives or motivators to test migrants for BBVs by over $50 \%$ of clinical staff (65\% response rate) (Table 2). Performance payment structure $(76.1 \%$, $181 / 238,70.2-81.0)$ had the greatest reported influence on testing, followed by PHE recommendations and CCG recommendations (both 73.1\%, 174/238, 67.1-78.3). Chief Medical Officer (CMO) recommendations (43.7\%, 104/238, 37.5-50.0) and NHS England (NHSE) recommendations $(44.5 \%, 105 / 235,38.3-50.9)$ had the least. CCG recommendations, local targets, NICE guidance and national goals were all endorsed by a significantly higher proportion of nurses than GPs as incentives or motivators $(p<0.05)$.

\section{Management of patients diagnosed with hepatitis B and C} All persons positive for HBV were referred to secondary care by $91.7 \%(99 / 108,84.9-95.6)$ of GPs and $67.0 \%$ (77/ $115,57.9-74.9)$ of nurses $(p<0.01)$ and this was $94.4 \%$ $(102 / 108,88.4-97.4)$ and $67.8 \%(78 / 115,58.8-75.7)$ respectively for persons positive for $\mathrm{HCV}(\mathrm{p}<0.01)$, with a higher proportion of nurses $(28.7 \%, 33 / 115,21.2-37.5)$ than GPs $(0.9 \%, 1 / 108,0.2-5.1)$ reporting they didn't know for both questions) ( $<<0.01,54 \%$ response rate) (Table 2). Information on whether the patient had attended was received by $62.0 \%(67 / 108,52.6-70.6)$ of GPs and $48.7 \%(56 / 115,39.8-57.7)$ of nurses $(\mathrm{p}<0.01)$ and $52.8 \%(57 / 108,43.4-61.9)$ of GPs and $40.9 \%$ (47/ $115,32.3-50.0)$ of nurses followed up patients who had not attended $(\mathrm{p}<0.01)$. Close contacts of HBV infected cases were offered testing by $74.1 \%(80 / 108,65.1-81.4)$ of GPs and $70.4 \%(81 / 115,61.5-78.0)$ of nurses $(p=$ $0.544)$, and vaccination by $73.1 \%(79 / 108,64.1-80.6)$ and $74.8 \%(86 / 115,66.1-81.8)$ respectively $(p=0.781)$.

\section{Practice policy}

Practice policy for offering BBV testing to migrant patients

HBV testing was offered on a universal/opt-out basis to all newly registering migrant patients by $17.8 \%(46 / 258$, 13.6-23.0) of respondents, with $17.1 \%$ (44/257, 13.022.2) for $\mathrm{HCV}$ and $20.9 \%(54 / 258,16.4-26.4)$ for HIV (all 62\% response rate, $p=0.498$ ) (Table 3). For existing patients who were migrants this was significantly lower: $11.2 \%(29 / 258,7.9-15.7)$ for HBV $(p=0.045), 10.7 \%$ (27/ $252,7.5-15.1)$ for $\operatorname{HCV}(p=0.041)$ and $14.0 \%(36 / 258$, 10.3-18.7) for HIV $(p=0.048)$ (62\% response rate for HBV and HIV, 61\% for HCV). Universal opt-out testing for newly registering migrant patients was significantly higher where respondents saw migrant patients frequently; 36.2\% (34/94, 27.2-46.2) for HBV, 35.5\% (33/ 93, 26.5-45.6) for HCV and 41.5\% (39/54, 32.1-51.6) for HIV than where they saw them sometimes or rarely; 7.9\% (13/164, 4.7-13.1) for HBV, 7.3\% (12/164, 4.212.4) for HCV and 9.8\% (16/164, 6.1-15.3) for HIV, $p<$ 0.0001 ), and was higher in small practices, with a similar pattern for existing migrant patients.

Testing practices varied by PHE region. Practice policy for offering universal opt-out HIV testing for newly registering migrant patients ranged from $53.1 \%(17 / 32,36.4-69.1)$ of respondents in Yorkshire and the Humber to $4.9 \%$ (2/41, 1.36.1) of respondents in the South East $(\mathrm{p}<0.0001)$, and this regional pattern was similar for HBV and HCV (supplementary Table 1). For existing patients who were migrants, universal opt-out testing was highest in the Midlands (31.7\%, $13 / 41,19.6-47.0$ for HIV) and lowest in the South East (4.9\%, 2/41, 1.3-16.1 for HIV), $p<0.05$ for all three BBV.

\section{Identification of migrant patients for BBV testing}

When asked if existing migrant patients were identified for testing opportunistically during consultation, 78.9\% $(191 / 242,73.4-83.6)$ of respondents stated they were (61\% response rate), while only $13.6 \%$ (33/242, 9.9-18.5) stated that systematic identification methods, either 
periodic flagging of the GP system by automated software, or periodic manual audit of the GP system, were used (61\% response rate) (Table 3). Flagging was significantly higher among those who saw migrant patients frequently $(20.0 \%, 18 / 90,13.0-29.4)$ than those who saw migrant patients sometimes/rarely $(9.9 \%, 15 /$ $152,6.1-15.6, p=0.026)$, and in small practices $(26.3 \%, 10 / 38,15.0-42.0)$ compared to medium $(9.5 \%$, $4 / 42,3.8-22.1)$ or large $(10.0 \%, 7 / 70,4.9-19.2)(p=$ $0.04)$ and was highest in Yorkshire and the Humber $(25.0 \%, 8 / 32,13.3-42.1)$ and London $(22.5 \%, 9 / 40$, $12.3-37.5)$ and lowest in the South East $(0.0 \%, 0 / 15$, $0.0-20.4)$, South West $(2.6 \%, 1 / 38,0.5-13.5)$, and North West $(3.1 \%, 1 / 32,0.6-15.7)(p=0.012)$ (supplementary Table 1).

\section{Services offered}

Most (87.5\%, 133/152, 81.3-91.8) practices provided interpreter services (38\% response rate), and $22.0 \%$ (53/ $241,17.2-27.6)$ offered longer appointments to migrants at registration (61\% response rate), but few offered other services to facilitate BBV testing and care of migrants (Table 4): 9.5\% (23/241, 6.4-13.9) had a specially designated clinic; $8.7 \%(21 / 241,5.8-13.0)$ had a designated GP; $11.6 \%(28 / 241,8.2-16.3)$ had specific projects to register migrants; $8.3 \%(20 / 241,5.4-12.5)$ had outreach facilities, $7.5 \%(18 / 241,4.8-11.5)$ had health support teams and $4.6 \%(11 / 241,2.6-8.0)$ had incentive schemes for GPs. Outreach services $(p=0.024)$ and projects to register migrants $(p=0.019)$ were both more common in small practices, and projects to register new migrants, specially designated clinics, longer appointments at registration (all $p<0.01$ ) and outreach services ( $p=$ $0.029)$ were all more common in practices where respondents saw migrant patients frequently. Provision of longer appointments at registration varied significantly by region and was highest in Yorkshire and Humber (46.9\%, 15/32, 30.9-63.6), followed by the North East $(41.7 \%, 5 / 12,19.3-68.0)$ and was lowest in the North West $(6.3 \%, 2 / 32,1.7-20.1) \quad(\mathrm{p}<0.01) \quad$ (supplementary Table 2).

\section{Routine recording of data}

Ethnicity was routinely recorded by $90.1 \%$ (137/152, 84.4-93.1) of respondents' practices, whereas 58.6\% (89/ $152,50.6-66.1)$ reported that they routinely recorded country of birth ( $38 \%$ response rate), and this was significantly higher where respondents saw migrant patients frequently $(\mathrm{p}<0.01)$ and in small practices $(p=$ 0.042 ) (Table 4). Hepatitis diagnosis was routinely recorded by $74.3 \%(113 / 152,66.9-80.3)$, and hepatitis prescription by $53.9 \%(82 / 152,46.0-61.7)$ of respondents' practices (Table 4).

\section{Perceived barriers for migrants to access healthcare across the care pathway}

The content and proportion of responses in each theme varied according to which part of the care pathway was considered (Fig. 1, additional file 4).

For perceived barriers for migrants accessing healthcare $(74 \%$ response rate), language and culture (predominantly language) were the most commonly reported $(74.4 \%, 218 / 293,69.1-79.1)$, followed by patient information and knowledge, particularly of the availability of health services and how to navigate the health system $(54.9 \%, 161 / 293,49.2-60.5)$, and psychological barriers, including fear $(15.7 \%, 46 / 293$, 12.0-20.3) (Fig. 1). Other common themes included accommodation or having no fixed abode $(8.2 \%, 24 /$ 294, 5.5-11.9), prejudice and discrimination (7.5\%, $22 / 293,5.0-11.1)$, and patient financial barriers $(10.2 \%, 30 / 293,7.3-14.2)$.

Language and culture was also the most commonly cited barrier to accessing BBV services in primary care (28.3\%, 67/237, 22.9-34.3, 60\% response rate) followed by resource issues $(27.0 \%, 64 / 237,21.8-33.0)$, and staff knowledge and awareness (25.7\%, 61/237, 20.6-31.7). Resource issues often related to time, whereas staff knowledge often related to a lack of staff training, or staff not being aware of patients' migrant status. Psychological barriers including stigma and fear of diagnosis were cited by $17.3 \%(41 / 237,13.0-226)$ of respondents, and service issues, such as practices not having a policy for BBV testing, or not identifying migrant patients, were given by $14.8 \%(35 / 237,10.8-19.8)$ of respondents.

For patients to access BBV services in secondary care, again language and culture was the most common theme $(41.5 \%, 98 / 236,35.4-47.9,60 \%$ response rate), followed by patient information and knowledge, with responses often relating to patients not understanding the significance of the diseases and importance of accessing treatment $(28.4 \%, 67 / 236,23.0-34.5)$. Geographical issues were cited by $24.5 \%$ (58/236, 19.5-30.4), including transport costs and lack of locally available services, and $21.2 \%(50 / 236,16.5-26.8)$ cited service issues, including communication methods around arranging appointments, waiting times and lack of an organised clinic.

Perceived barriers for asylum seekers accessing healthcare (74\% response rate) were largely similar to those for all migrants, with some notable differences (Fig. 2). Language and psychological barriers were more frequently reported for asylum seekers than they were for all migrants. Psychological barriers again included fear, as well as highlighting mental health concerns for asylum seekers. To a lesser degree, accommodation, and prejudice and discrimination were also identified more often for asylum seekers than for all migrants. 


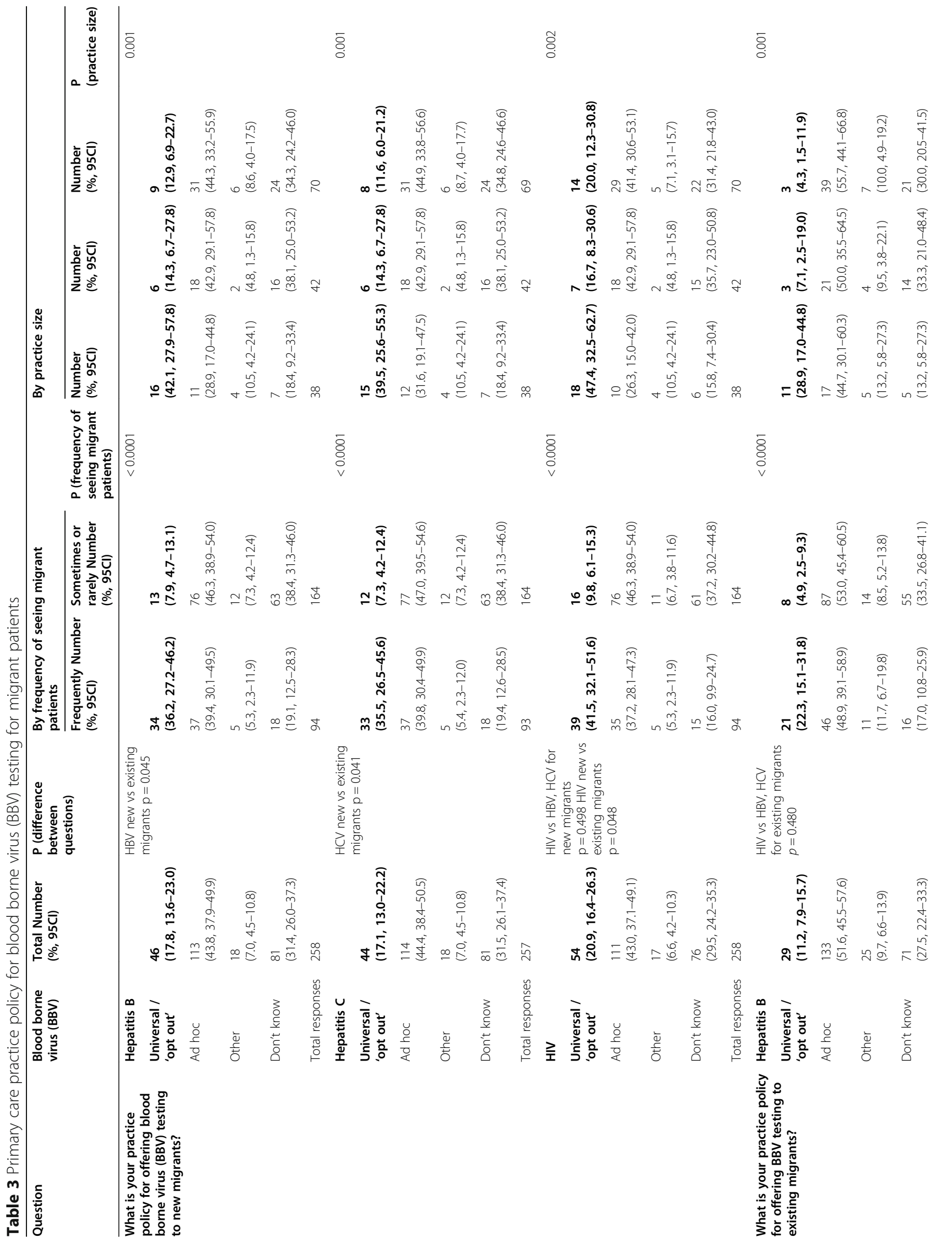




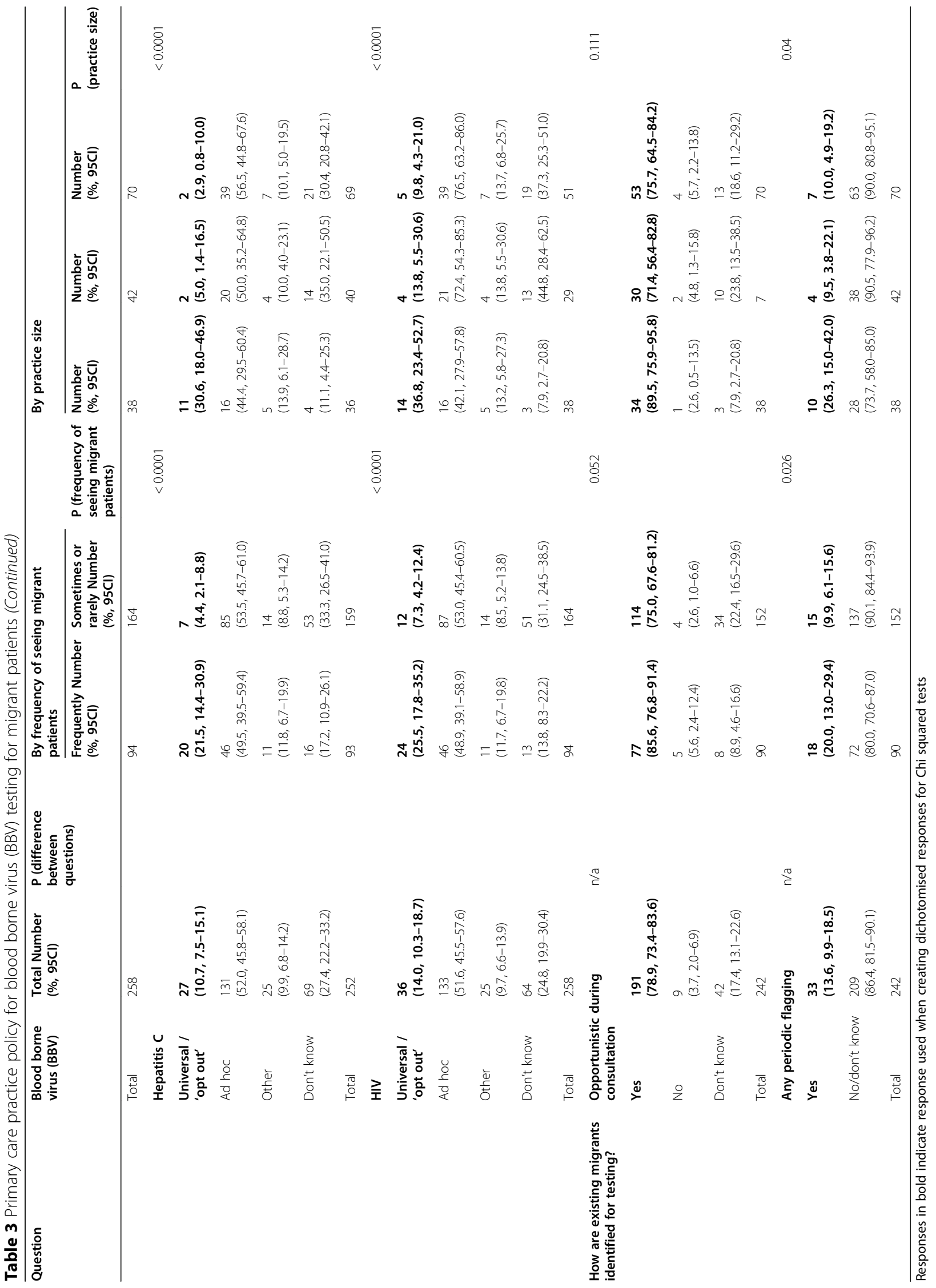




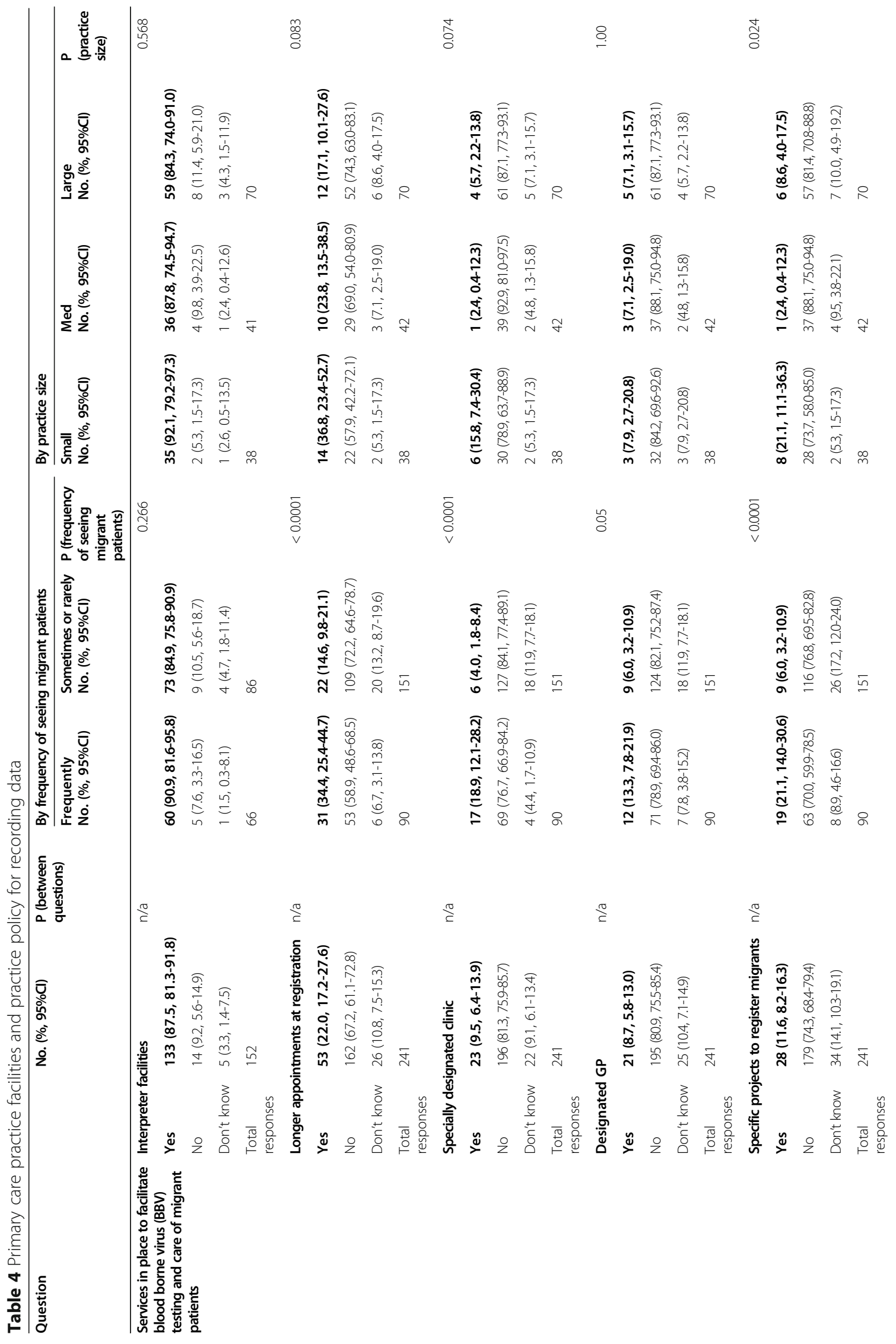




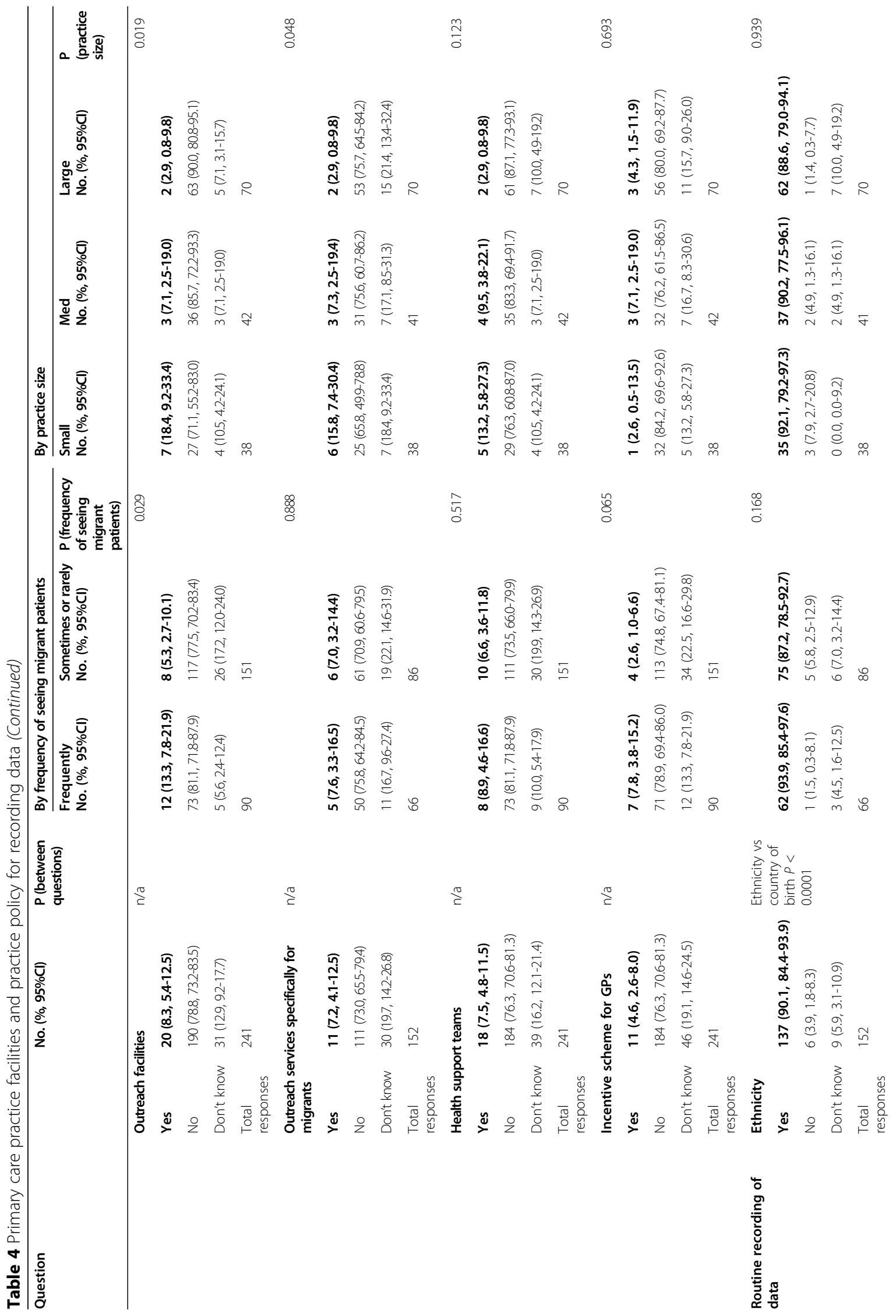




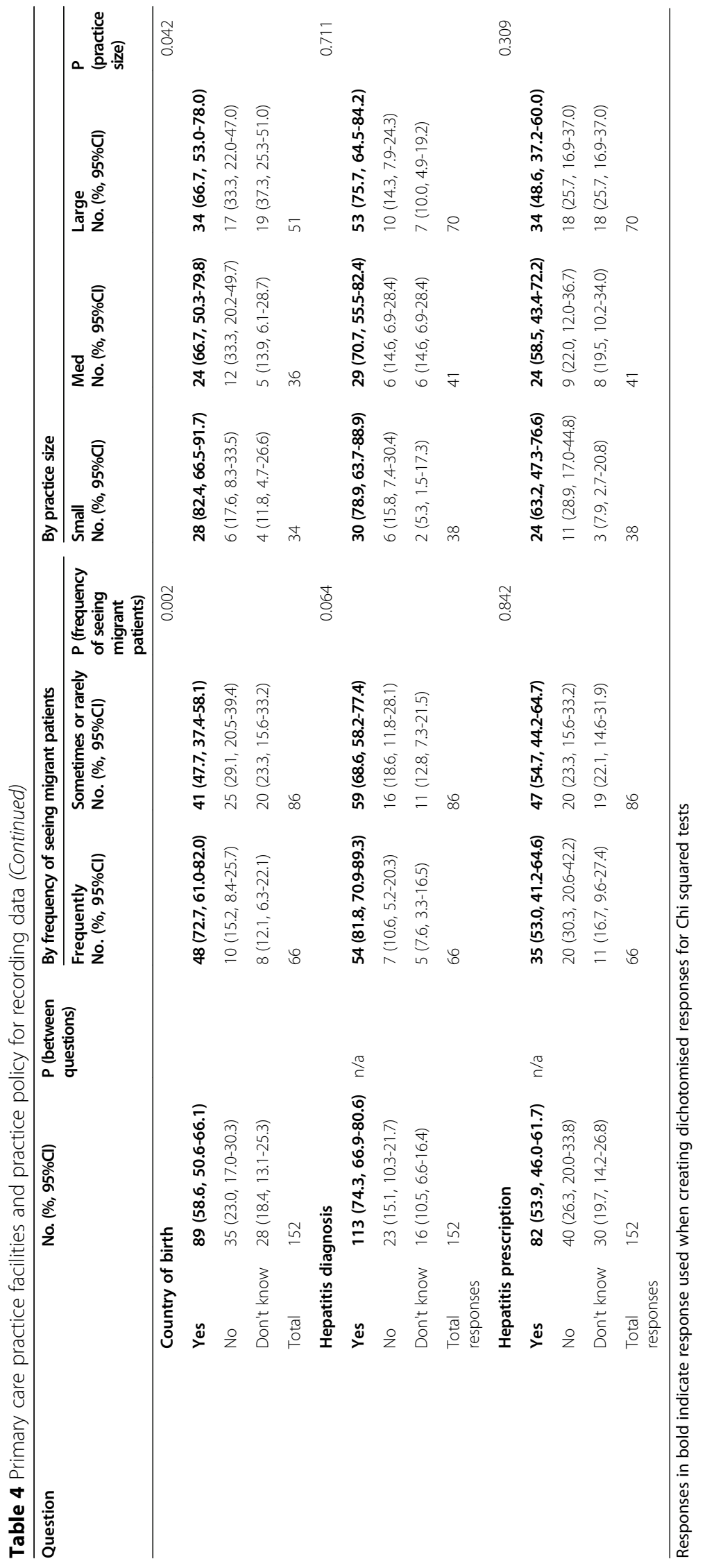




\section{Discussion}

Primary care staff knowledge, attitudes, policy and practice regarding migrants' healthcare entitlements and their BBV testing and care was very variable in this sample of English practices. One in four were unaware that GP and nurse consultations are free for all. Universal opt-out BBV testing for migrants was not common practice, and only one in three clinical staff would routinely consider BBV risk assessments for newly registering migrant patients. Where testing was requested, most respondents requested the recommended tests, and over $90 \%$ indicated they would refer diagnosed cases to secondary care. Respondents identified access barriers relating to a range of factors including language; patient knowledge, stigma and fear; time pressures of appointments, practices not having a BBV testing policy and lack of knowledge and awareness among staff.

Knowledge of entitlements to health services varied. Of particular concern is that a quarter of clinical staff were unaware that GP and nurse consultations are free to all. Vulnerable patients, including migrants could be wrongly refused GP registration, despite national guidance that lack of documentation should not be a barrier to registering with a GP [24]. Three UK studies estimate that refusal ranges from 20 to $39 \%$ [25-27]. As primary care is the first point of access, 'gatekeeper' to other services, and a trusted source of health information, GP staff's poor knowledge of entitlements is likely to create a further access barrier in addition to the system, cultural and language barriers migrants face, especially when it comes to communicable disease control [28, 29]. There were no substantial differences in knowledge of healthcare entitlements of migrants between GPs and nurses; GPs were more likely to know that operations and outpatient appointments are not free, and nurses were more likely to know that care for FGM, torture etc. is free, which likely reflects their roles in general practice.

BBV testing was more often conducted on an ad-hoc than opt-out basis, and BBV risk assessments for newly registering migrant patients were routinely considered by only a third of respondents, and more often considered on a situation specific basis. Most respondents stated existing migrant patients were identified for testing opportunistically during consultation, and only $14 \%$ systematically flagged migrant patients for BBV testing. These findings suggest that migrant patients eligible for BBV testing are not often routinely identified as such, which is likely to hinder adherence to BHIVA, ECDC and NICE guidelines which recommend BBV testing for migrant patients from higher $\mathrm{HBV}$ and $\mathrm{HCV}$ prevalence $(>=2 \%)$ areas and HIV testing for all patients in high ( $>$ 2 per 1000) prevalence areas in the UK [10, 11, 30], and is consistent with other studies which report low adherence to testing guidelines for BBVs outside of the sexual and antenatal health setting [12, 31]. Opt-out rapid testing in general practice has been shown to increase diagnosis rates for HIV, and universal optout testing initiatives for migrants which offer opportunities to normalise testing are subject to ongoing evaluations and have been well received by staff and patients [32-34].

Improved practice staff knowledge is needed to help reduce barriers and variations in service provision. Resources are available, such as the PHE Migrant Health Guide which outlines NHS entitlements and gives guidance on assessing new patients from overseas [35], RCGP e-learning courses [36], but also PHE and charities co-branded promotional videos, posters and leaflets on $\mathrm{BBV}$ in multiple languages for patient waiting areas can be downloaded or ordered from gov.uk [37]. Further work is needed to understand current awareness and to increase uptake of these resources.

Use of software programmes to identify and automatically flag patients for testing based on risk factors or risk proxies recorded on practice registers has been shown to be effective for groups including migrants in primary care and other settings [38-40]. This requires migrant status to be recorded on GP systems for migrants to be flagged as at risk. Although $59 \%$ of respondents stated that their practice routinely recorded country of birth, data from the Clinical Practice Research Datalink suggests recording is a lot lower at $1.6 \%$ [41]. This discrepancy could in part be due to biases in our sample or respondents giving socially desirable answers, however it may be that practices are recording this data on other systems where the data is not extractable. This highlights a need to increase awareness of the importance of recording patient country of birth amongst practitioners and information service providers, and for practitioners to assess risks associated with country of birth as a part of the first registration consultation.

Flagging and opt-out testing for newly registering migrant patients was more frequently reported where respondents said they see migrant patients frequently, in smaller practices and highest in Yorkshire and Humber and London, but lowest in the South East. A similar pattern was observed for services such as specially designated clinics, longer appointments at registration and projects to register migrants - these were more frequently reported where respondents saw migrants frequently. Outreach services and projects to register migrants were higher in small practices. These variations may reflect GP surgeries adopting policies and practices that reflect the needs and diversity of their local populations, and the ability of smaller practices to be more responsive and adaptive in implementing migrant focused services. 


\section{$\%$ of respondents (Healthcare $n=293$; BBV testing $n=237$; Secondary} care $n=236$ )

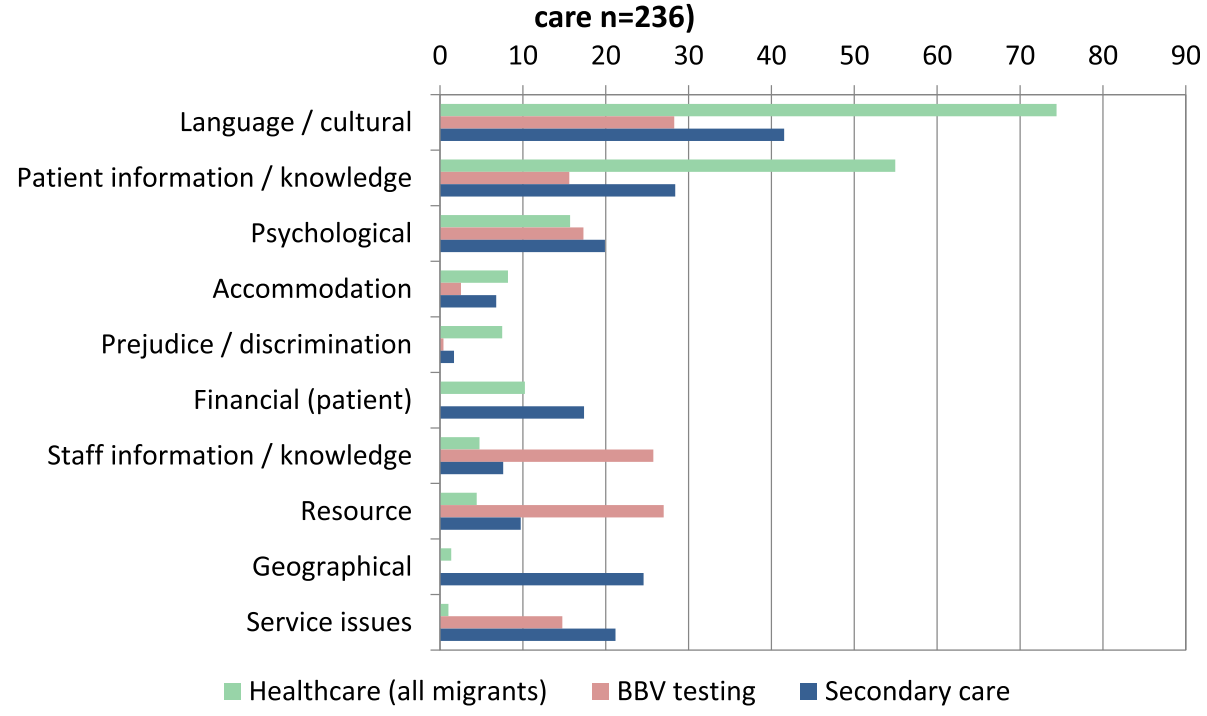

Fig. 1 Perceived barriers for migrant populations to access different parts of the BBV care pathway, England, 2017

Performance payment structure may be the most influential way to incentivise BBV testing [42-44], and PHE and CCG recommendations were also more often stated to provide motivation to test than alternative sources. Only half of respondents indicated that NHSE and $\mathrm{CMO}$ recommendations would provide motivation for testing, which may reflect a relative lack of confidence in these bodies versus the perceived scientific credibility and independence of PHE and the more direct relationship and understanding of local PHE teams with CCGs. Interestingly, nurses were more likely than GPs to be motivated by local targets, national goals, CCG recommendations and NICE guidance.
Over $90 \%$ of GPs reported referring diagnosed cases of $\mathrm{HBV}$ and HCV to secondary care, and over half followed patients up if they did not attend secondary care appointments. Three quarters would offer close contacts of HBV infected cases testing, and three quarters would offer close contacts hepatitis B vaccination. These proportions seem high, as many patients diagnosed with HBV and HCV are known not to be accessing secondary care - in a 2012 UK study only a third of HBV diagnosed patients were on treatment [45] and an analysis of England sentinel surveillance data showed that between 2004 and 2017 only $21 \%$ of viraemic HCV diagnosed patients had evidence of treatment [46], and baseline HBV

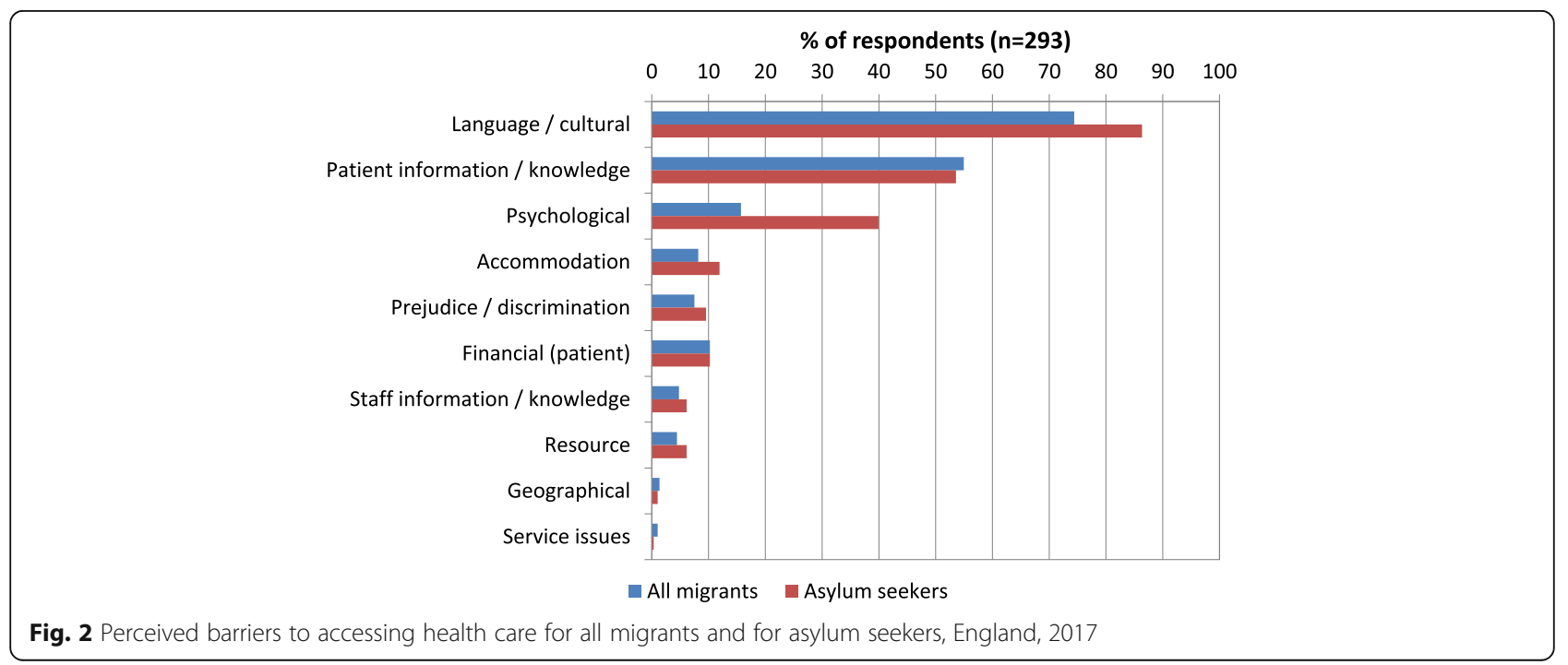


testing of close contacts was only $34 \%$ in a 2018 UK study [47]. Our results may be due to sampling and responder bias, due to initially contacting networks who were interested in migrant health, and those who were interested being more likely to respond, as well as wishing to give socially acceptable or desirable responses.

Differences in knowledge of BBV diagnosis and management were noted between nurses and GPs, with nurses being less likely to know whether all diagnosed $\mathrm{HBV} / \mathrm{HCV}$ patients are referred and whether referrals are followed up, and less likely to know the diagnostic tests to request for HCV and HIV but there was no significant difference for HBV. Generally, there is a need for improved understanding of diagnostic testing for BBV in practices. Regardless of service, respondents cited language as the main barrier to accessing healthcare, which is consistent with the literature [14, 15, 48]. For patients who require linguistic support, interpreting services are recommended in General Medical Council guidance and were provided by $88 \%$ of respondents' practices [49-51]. Nevertheless, there is evidence that interpreting services are underused, despite incurring no direct cost for practices [52]. This may be partly due to time pressures within appointments and the indirect costs of longer appointment times, as well as the need for forward planning and a lack of professional confidence in working with interpreters [53]. Brief education may help improve professional confidence in when and how to use interpreters [54]. Improved provision of translated materials is also likely to be beneficial in improving patient access to health information; efforts to ensure materials about BBV are translated are ongoing [55].

Patient knowledge and understanding of disease, and the location of secondary care services were cited as barriers to accessing secondary care. Community based treatment pathways, as have been demonstrated to be effective for HCV [56, 57], could help to overcome geographic barriers, although one recent study found that (first and second generation) migrant patients were no more likely to complete treatment on a community pathway [40]. Assessing patient attitudes towards BBV, and increasing patient knowledge would also be valuable and could be considered by practices to improve their services.

\section{Limitations}

This survey has a low response rate and a relatively small sample size, and may be affected by sampling and responder bias, as the survey was disseminated by contacts and networks with an interest in migrant and asylum seeker health and through a publication which professionals with an interest in vaccines subscribe to, so practice professionals with interests in migrant health,
BBVs and vaccine preventable diseases may have been more likely to respond. This is likely to bias the responses towards more knowledge of healthcare entitlements and better practices for BBV screening and management of migrants. Response to recruitment at professional conferences was poor, possibly due to competing priorities for professionals with limited time in a conference setting.

No demographic data on respondents was collected, so it was not possible to assess how responses vary by individual respondent characteristics, which may have associations with personal bias, stigma and discrimination against individuals who have migrated from specific countries or settings.

Our findings may therefore not be representative of all general practice staff. It was not possible to obtain data on non-respondents which would help to identify biases in responses; further work to survey practitioners within a fixed sampling frame (for example all GP practices in one CCG) may help to address this issue. In addition, not all questions were completed by all participants and fewer respondents completed later questions in the survey. Again, those more motivated may be more likely to complete the whole survey, leading to potentially greater bias in questions that had fewer respondents.

The small sample size limited our power to detect statistically significant differences between subgroups, particularly in detecting regional variations. Increasing the responses to the survey would help to address this, and in hindsight, following up the circulation of the survey link in Vaccine Updates could have helped to increase sample size and potentially reduce response bias.

Another limitation was that questions about barriers for migrant patients were asked to general practice professionals rather than migrants themselves; responses will reflect only barriers that these professionals were aware of and may exclude those which migrants experience, but professionals are less aware of. However, our findings echoed those cited by migrants in a qualitative study on barriers to accessing healthcare for viral hepatitis [14], which suggests that our respondents were relatively well informed about these issues.

\section{Conclusions}

Systematic or universal opt-out testing for migrant patients are uncommon and testing is more often done on an ad hoc basis, despite BASHH, PHE and NICE guidelines. Achieving the WHO goal of eliminating viral hepatitis as a public health threat by 2030 requires coordinated efforts to increase case-finding of patients with HBV and $\mathrm{HCV}$; our results suggest that current testing practices for high-risk migrants in primary care are likely to be inadequate to meet the elimination goal among this population. Improved systematic risk-based flagging of migrant 
patients for BBV screening and checks or prompts for referral and attendance to specialist services is needed to reduce the burden of undiagnosed infection and improve uptake of treatment, noting this is curative for hepatitis C. Local and national commissioning specifications for primary care testing and management of BBV infected patients may be required to achieve this goal. General practice professionals' knowledge of migrants' entitlements to healthcare was variable and could affect migrants' access to care. Perceived barriers to accessing healthcare consistently included language and lack of patient and staff information and awareness. These are not insurmountable but require sustained commitment, professional awareness as well as resource. The ultimate goal is to reduce morbidity, mortality and inequalities associated with BBV infections in migrant populations, mindful of the fact that this population is already vulnerable to disparities in healthcare access and health outcomes.

\section{Supplementary Information}

The online version contains supplementary material available at https://doi. org/10.1186/s12889-020-10068-X.

Additional file 1. Full online questionnaire. Text version of the online questionnaire used for the survey.

Additional file 2. Shorter paper questionnaire. PDF of the paper questionnaire that was distributed at the RCGP and Best Practice in Primary Care conferences.

Additional file 3. Definitions sheet which accompanied the questionnaire.

Additional file 4. Example responses for barriers questions. Example responses for free text barriers questions, by theme and part of care pathway.

\section{Abbreviations \\ Anti-HCV: Antibodies against hepatitis C virus; BASHH: British Association of Sexual Health and HIV; BBV: Blood borne virus; BHIVA: British HIV Association; CCG: Clinical commissioning group; CMO: Chief Medical Officer; DBS: Dried blood spot; ECDC: European Centre for Disease Prevention and Control; ED: Emergency department; GP: General practitioner; HBCAb: Hepatitis B core antibody; HBsAg: Hepatitis B surface antigen; HBV: Hepatitis B virus; HCV: Hepatitis C virus; HCV RNA: Hepatitis C virus ribonucelic acid; HIV: Human immunodeficiency virus; NICE: National Institute for Health and Care Excellence; PHE: Public Health England; TB: Tuberculosis; UK: United Kingdom; WHO: World Health Organisation}

\section{Acknowledgements}

We acknowledge members of the NIHR HPRU in BBSTI Steering Committee: Caroline Sabin, John Saunders, Catherine H. Mercer, Gwenda Hughes, Greta Rait, Jackie Cassell, William Rosenberg, Tim Rhodes, Kholoud Porter, Samreen ljaz and Sema Mandal.

We are very grateful to all those who participated in the survey. We also thank those on the project group who helped design the questions, and those who were involved in dissemination of the survey.

\section{Authors' contributions}

SM came up with the initial concept. RS RR SM implemented and managed the study. All authors apart from MP reviewed the questionnaire. RR undertook the analysis and had access to the complete dataset. RR and RS drafted the initial manuscript. SM provided critical input into the manuscript. All authors reviewed and approved the final manuscript.

\section{Funding}

The research was funded by the National Institute for Health Research Health Protection Research Unit [NIHR HPRU] in Blood Borne and Sexually Transmitted Infections at UCL in partnership with PHE and in collaboration with the London School of Hygiene and Tropical Medicine (LSHTM). The views expressed are those of the authors and not necessarily those of the NIHR, the Department of Health and Social Care or Public Health England. MP is supported by the National Institute for Health Research (NIHR PostDoctoral Fellowship, Dr. Manish Pareek, PDF-2015-08-102). The funders had no role in study design, data collection and analysis, or preparation of the manuscript. The final draft was circulated with the NIHR HPRU steering group prior to submission. AFC is funded by the Academy of Medical Sciences (SBF005\1111) and the NIHR (NIHR300072).

\section{Availability of data and materials}

The datasets used and analysed during the current study are available from the corresponding author on reasonable request.

\section{Ethics approval and consent to participate}

this project was subject to an internal review by the Research Support and Governance Office in PHE to ensure that it was fully compliant the NHS Research Governance Framework for Health and Social Care (April 2005), and with all other current regulatory requirements. The review also covered all ethical considerations. The study was categorized as a service evaluation, and as no ethical issues had been identified it was decided that review by an ethics committee would not be necessary. This is in accordance with the revised guidance in the Governance Arrangements for Research Ethics Committees (GAfREC) that was released in September 2011. Online surveys typically do not require consent; information was given to the participants about the survey before completion, with the completion of any of the questions taken as consent.

\section{Consent for publication}

Not applicable as no sensitive personal information was collected.

\section{Competing interests}

The authors declare that they have no competing interests.

\section{Author details}

'Blood Safety, Hepatitis, Sexually Transmitted Infections (STI) and HIV Service, National Infection Service, Public Health England, 61 Colindale Avenue, London NW9 5EQ, UK. ${ }^{2}$ The National Institute for Health Research Health Protection Research Unit (NIHR HPRU) in Blood Borne and Sexually Transmitted Infections at University College London, Gower St, London WC1E 6BT, UK. ${ }^{3}$ Migration Health, Health Improvement, Public Health England, Wellington House, 133-155 Waterloo Road, London SE1 8UG, UK. ${ }^{4}$ Institute for Infection and Immunity, St George's, University of London, Cranmer Terrace, Tooting, London SW17 ORE, UK. ${ }^{5}$ University of Manchester, Oxford Road, Manchester M13 9PL, UK. ${ }^{6}$ Department of Respiratory Sciences, University of Leicester, University Road, Leicester LE1 7RH, UK. ${ }^{7}$ Public Health England Yorkshire and the Humber, 2nd Floor, Blenheim House, Duncombe Street, Leeds LS1 4PL, UK. ${ }^{8}$ Public Health England North West, 2nd Floor, 3 Piccadilly Place, London Road, Manchester M1 3BN, UK. Institute of Epidemiology and Healthcare, University College London (UCL), 1-19 Torrington Place WC1E 7HB, London, UK.

Received: 27 February 2020 Accepted: 14 December 2020 Published online: 11 February 2021

\section{References}

1. Cochrane A, Evlampidou I, Irish C, Ingle SM, Hickman M. Hepatitis B infection prevalence by country of birth in migrant populations in a large UK city. J Clin Virol. 2015;68:79-82 Available from: https://europepmc.org/ article/med/26071342.

2. Public Health England. Progress towards ending the HIV epidemic in the United Kingdom, 2018 report. 2018. Available from: https:/assets.publishing. service.gov.uk/government/uploads/system/uploads/attachment_data/file/ 759408/HIV_annual_report_2018.pdf. Accessed on 09 Mar 2019.

3. Mann AG, Trotter CL, Adekoyejo Balogun M, Ramsay ME. Hepatitis C in ethnic minority populations in England. 2008;15(6):421-6 Available from: 
https:/onlinelibrary.wiley.com/doi/abs/10.1111/j.1365-2893.2007.00958.x. Accessed on 14 May 2019

4. Hahne S, Ramsay M, Balogun K, Edmunds WJ, Mortimer P. Incidence and routes of transmission of hepatitis B virus in England and Wales, 1995-2000: implications for immunisation policy. J Clin Virol. 2004;29(4):211-20.

5. Costella A, Balogun $\mathrm{K}$, Andrews N, Mandal S, Harris H. Hepatocellular Carcinoma Deaths in England with Chronic Hepatitis B and Hepatitis C Infection, Faculty of Public Health Annual Conference and Public Health Exhibition; 14-15 June 2016. Brighton: Brighton Centre; 2016.

6. Public Health England. 2nd Atlas of Variation in risk factors and healthcare for liver disease in England. London; 2017. Available from: http://fingertips. phe.org.uk/profile/atlas-of-variation. Accessed on 12 Feb 2018.

7. Kirwan P, Chau C, Brown A, Gill O, Delpech V, and contributors. HIV in the UK 2016 report. London: Public Health England; 2016. Available from: https:/assets. publishing.service.gov.uk/government/uploads/system/uploads/attachment_ data/file/602942/HIV_in_the_UK_report.pdf. Accessed on 20 Feb 2018.

8. Moorman AC, Xing J, Ko S, Rupp LB, Xu F, Gordon SC, et al. Late diagnosis of hepatitis C virus infection in the Chronic Hepatitis Cohort Study (CHeCS): Missed opportunities for intervention. Hepatology (Baltimore, Md). 2015; 61(5):1479-84 Available from: https://pubmed.ncbi.nlm.nih.gov/25131217/.

9. World Health Organisation. Global Health Sector Strategy on Viral Hepatitis 2016-2021: towards ending viral hepatitis. 2016. Available from: http://apps. who.int/iris/bitstream/10665/246177/1/WHO-HIV-2016.06-eng.pdf?ua=1. Accessed on 12 Feb 2018.

10. NICE. Hepatitis B and C testing: people at risk of infection: Public health guideline [PH43]. 2012 Available from: https://www.nice.org.uk/guidance/ ph43. Accessed on 20 Feb 2018.

11. European Centre for Disease Prevention and Control. Public health guidance on screening and vaccination for infectious diseases in newly arrived migrants within the EU/EEA. 2018. Available from: https://ecdc. europa.eu/en/publications-data/public-health-guidance-screening-andvaccination-infectious-diseasesnewly. Accessed on 12 Mar 2019

12. Evlampidou I, Hickman M, Irish C, Young N, Oliver I, Gillett S, et al. Low hepatitis B testing among migrants: a cross-sectional study in a UK city. Brit J General Pract. 2016;66(647):e382-91 Available from: https://www.ncbi.nlm. nih.gov/pmc/articles/PMC4871303/pdf/bjgpjun-2016-66-647-e382.pdf.

13. Public Health England. Annual report from the sentinel surveillance study of blood borne virus testing in England: data for January to December 2015. 2016. Available from: https://www.gov.uk/government/uploads/system/uploads/ attachment_data/file/540332/hpr2416_bbvs.pdf. Accessed on 24 Oct 2017.

14. Guirgis M, Nusair F, Bu YM, Yan K, Zekry AT. Barriers faced by migrants in accessing healthcare for viral hepatitis infection. Intern Med J. 2012;42(5): 491-6 Available from: http://onlinelibrary.wiley.com/doi/10.1111/j.1445-5 994.2011.02647.x/abstract.

15. Cochrane A, Collins P, Horwood JP. Barriers and opportunities for hepatitis B testing and contact tracing in a UK Somali population: a qualitative study. Eur J Pub Health. 2016;26(3):389-95 Available from: https:/doi.org/10.1093/ eurpub/ckv236.

16. Rechel B, Mladovsky P, Ingleby D, Mackenbach JP, McKee M. Migration and health in an increasingly diverse Europe. Lancet. 2013;381 (9873):1235-45 Available from: http://www.sciencedirect.com/science/article/pii/S01406 73612620868 .

17. Hacker K, Anies M, Folb BL, Zallman L. Barriers to health care for undocumented immigrants: a literature review. Risk Manag Healthc Policy. 2015;8:175-83 Available from: https:/www.dovepress.com/getfile.php?filelD=27788.

18. The National Health Service. (Charges to Overseas Visitors) (Amendment) Regulations 2017, Stat. 238. 2017.

19. Department of Health. Guidance on overseas visitors hospital charging regulations. 2017. Available from: https://www.gov.uk/government/ publications/guidance-on-overseas-visitors-hospital-charging-regulations. Accessed on 23 Nov 2017.

20. The National Health Service. (Charges to Overseas Visitors) Regulations 2015, Regulation 9, Schedule 1. 2015

21. UN. Refugees and Migrants - definitions. 2020. Available from: https:// refugeesmigrants.un.org/definitions. Accessed on 09 Oct 2020.

22. UNHCR. UNHCR Global Report 2005 - Glossary. 2005. Available from: https:// www.unhcr.org/449267670.pdf.

23. NHS Digital. GP and GP practice related data, GP Practices (eppraccur), December 2017. 2017. Available from: https://digital.nhs.uk/services/ organisationdata-service/data-downloads/gp-and-gp-practice-related-data. Accessed on 24 Aug 2020.
24. NHS England. Patient registration: standard operating principles for primary medical care (general practice). 2015

25. Doctors of the World. Registration refused: A study on access to GP registration in England - Part 1. 2015. Available from: https://www. doctorsoftheworld.org.uk/publications/\#. Accessed on 02 May 2018.

26. Doctors of the World. Registration refused: A study on access to GP registration in England - Part 2. 2016. Available from: https://www. doctorsoftheworld.org.uk/publications/\#. Accessed on 02 May 2018.

27. Doctors of the World. Registration refused: A study on access to GP registration in England - update 2017. 2017. Available from: https://www. doctorsoftheworld.org.uk/publications/\#. Accessed on 14 May 2018.

28. NHS England, Ipsos Mori. GP patient survey 2017. 2017. Available from: https://www.england.nhs.uk/statistics/2017/07/06/gp-patient-survey-2017/. Accessed on 04 May 2018.

29. NHS England. GP patient survey 2018. 2018. Available from: https://gppatient.co.uk/surveysandreports. Accessed on 09 Dec 2018.

30. British HIV Association (BHIVA). UK National Guidelines for HIV Testing 2008. 2008. Available from: https://www.bhiva.org/file/RHNUJglseDaML/ GlinesHIVTest08.pdf.

31. Elmahdi R, Gerver SM, Gomez Guillen G, Fidler S, Cooke G, Ward H. Low levels of HIV test coverage in clinical settings in the U.K.: a systematic review of adherence to 2008 guidelines. Sex Transm Infect. 2014;90(2):11924 Available from: https://pubmed.ncbi.nlm.nih.gov/24412996/.

32. Pareek M, Eborall HC, Wobi F, Ellis KS, Kontopantelis E, Zhang F, et al. Community-based testing of migrants for infectious diseases (COMBAT-ID): impact, acceptability and cost-effectiveness of identifying infectious diseases among migrants in primary care: protocol for an interrupted time-series, qualitative and health economic analysis. BMJ Open. 2019;9(3):e029188 Available from: http://bmjopen.bmj.com/content/9/3/e029188.abstract.

33. Leber W, McMullen H, Anderson J, Marlin N, Santos AC, Bremner S, et al. Promotion of rapid testing for HIV in primary care (RHIV A2): a clusterrandomised controlled trial. Lancet HIV. 2015;2(6):e229-35 Available from: https://pubmed.ncbi.nlm.nih.gov/26423195/.

34. Eborall H, Wobi F, Ellis K, Willars J, Abubakar I, Griffiths C, et al. Integrated screening of migrants for multiple infectious diseases: qualitative study of a city-wide programme. EClin Med. 2020;21 Available from: https://doi.org/10. 1016/j.eclinm.2020.100315. Accessed on 26 Aug 2020.

35. Public Health England. Migrant Health Guide. Available from: https://www.gov. uk/topic/health-protection/migrant-health-guide. Accessed on 20 Oct 2020.

36. RCGP. RCGPLearning: essential CPG for primary care. Available from: http:// elearning.rcgp.org.uk/. Accessed on 18 Mar 2019.

37. Public Health England. Immunisation App Box: Eliminate Hepatitis B and C resources. 2018. Available from: https://publichealthenglandimmunisati.app. box.com/s/iptxtlziu57evyejw8zgvhimh0pjwa05. Accessed on 04 July 2019.

38. Federman AD, Kil N, Kannry J, Andreopolous E, Toribio W, Lyons J, et al. An electronic health record-based intervention to promote hepatitis $C$ virus testing among adults born between 1945 and 1965: a cluster-randomized trial. Med Care. 2017;55(6):590-7 Available from: https://www.ncbi.nlm.nih. gov/pubmed/28288075. https:/www.ncbi.nlm.nih.gov/pmc/PMC5759753/.

39. Golden MR, Duchin J, Chew LD, Huntington JH, Sugg N, Jackson S, et al. Impact of an electronic medical record-based system to promote human immunodeficiency virus/hepatitis $C$ virus screening in public hospital primary care clinics. Open Forum Infect Dis. 2017;4(2):ofx075 Available from: https://www.ncbi.nlm.nih.gov/pubmed/28584856.

40. Flanagan S, Kunkel J, Appleby V, Eldridge SE, Ismail S, Moreea S, et al. Case finding and therapy for chronic viral hepatitis in primary care (HepFREE): a cluster-randomised controlled trial. Lancet Gastroenterol Hepatol. 2019;4(1): 32-44 Accessed 14/06/2019.

41. Jain A, van Hoek AJ, Walker JL, Mathur R, Smeeth L, Thomas SL. Identifying social factors amongst older individuals in linked electronic health records: an assessment in a population based study. PLOS ONE. 2017;12(11): e0189038 Available from: https://doi.org/10.1371/journal.pone.0189038.

42. Allen $T$, Whittaker $W$, Kontopantelis $E$, Sutton M. Influence of financial and reputational incentives on primary care performance: a longitudinal study. Br J Gen Pract. 2018;68(677):e811 Available from: http://bjgp.org/content/6 8/677/e811.abstract.

43. Steel N, Maisey S, Clark A, Fleetcroft R, Howe A. Quality of clinical primary care and targeted incentive payments: an observational study. Brit I General Practice. 2007;57(539):449-54 Available from: https://pubmed.ncbi.nlm.nih. gov/17550669. https://www.ncbi.nlm.nih.gov/pmc/articles/PMC2078183/. 
44. Roland M, Olesen F. Can pay for performance improve the quality of primary care? BMJ. 2016;354 Available from: https://www.bmj.com/ content/354/bmj.i4058.full.print. Accessed 18 Aug 2020.

45. Tedder RS, Rodger AJ, Fries L, ljaz S, Thursz M, Rosenberg W, et al. The diversity and Management of Chronic Hepatitis B Virus Infections in the United Kingdom: a wake-up call. Clin Infect Dis. 2013;56(7):951-60 Available from: https://doi.org/10.1093/cid/cis1013.

46. Simmons R, Ireland G, Irving W, Hickman M, Sabin C, ljaz S, et al. Establishing the cascade of care for hepatitis $C$ in England - benchmarking to monitor impact of direct acting antivirals. J Viral Hepat. 2018;25(5):482-90 Available from: https:/onlinelibrary.wiley.com/doi/abs/10.1111/jvh.12844.

47. Beebeejaun K, Amin-Chowdhury Z, Letley L, Kara E, Mahange B, Harrington $K$, et al. Impact of a nurse-led enhanced monitoring, management and contact tracing intervention for chronic hepatitis B in England, 2015-2017. J Viral Hepat. 2020;00:1-8 Available from: https://onlinelibrary.wiley.com/doi/ $\mathrm{abs} / 10.1111 / \mathrm{jvh} .13403$.

48. Falla AM, Veldhuijzen IK, Ahmad AA, Levi M, Richardus JH. Language support for linguistic minority chronic hepatitis B/C patients: an exploratory study of availability and clinicians' perceptions of language barriers in six European countries. BMC Health Serv Res. 2017;17:150 Available from: http://www.ncbi.nlm.nih.gov/pmc/articles/PMC5319068/. https://www.ncbi. nlm.nih.gov/pmc/articles/PMC5319068/pdf/12913_2017_Article_2095.pdf.

49. Karliner LS, Jacobs EA, Chen AH, Mutha S. Do professional interpreters improve clinical care for patients with limited English proficiency? A systematic review of the literature. Health Serv Res. 2007;42(2):727-54 Available from: https://www.ncbi.nlm.nih.gov/pmc/articles/PMC1955368/ pdf/hesr0042-0727.pdf.

50. NHS England. NHS Commissioning: Interpreting and translation in primary care. 2019. Available from: https://www.england.nhs.uk/commissioning/ primarycare/primary-care-comm/interpreting/. Accessed 18 Mar 2019.

51. General medical council. Good medical practice. Domain 3: Communication partnership and teamwork. 2019.

52. Gill PS, Beavan J, Calvert M, Freemantle N. The unmet need for interpreting provision in UK primary care. PLoS One. 2011;6(6):e20837 Available from: https:// www.ncbi.nlm.nih.gov/pmc/articles/PMC3113854/pdf/pone.0020837.pdf.

53. Kai J. Enhancing consultations with interpreters: learning more about how. Brit J General Practice. 2013;63(607):66-7 Available from: https://www.ncbi. nlm.nih.gov/pubmed/23561659. https://www.ncbi.nlm.nih.gov/pmc/ PMC3553612/.

54. Jacobs EA, Diamond LC, Stevak L. The importance of teaching clinicians when and how to work with interpreters. Patient Educ Couns. 2010;78(2): 149-53 Available from: https://www.sciencedirect.com/science/article/pii/ S0738399109005916?via\%3Dihub.

55. Public Health England. Protecting your baby against hepatitis B leaflet. 2018. Available from: https:/www.gov.uk/government/publications/protectingyourbaby-against-hepatitis-b-leaflet.

56. Radley A, Tait J, Dillon JF. DOT-C: A cluster randomised feasibility trial evaluating directly observed anti-HCV therapy in a population receiving opioid substitute therapy from community pharmacy. Int J Drug Policy. 2017;47:126-36 Available from: http://ovidsp.ovid.com/ovidweb.cgi?T= JS\&PAGE=reference\&D=med13\&NEWS=N\&AN=28647161.

57. Wade AJ, Veronese V, Hellard ME, Doyle JS. A systematic review of community based hepatitis C treatment. Bmc Infect Dis. 2016;16:202 Available from: http://ovidsp.ovid.com/ovidweb.cgi?T=JS\&PAGE= reference\&D $=$ med $12 \& N E W S=N \& A N=27184661$.

\section{Publisher's Note}

Springer Nature remains neutral with regard to jurisdictional claims in published maps and institutional affiliations.

Ready to submit your research? Choose BMC and benefit from:
- fast, convenient online submission
- thorough peer review by experienced researchers in your field
- rapid publication on acceptance
- support for research data, including large and complex data types
- gold Open Access which fosters wider collaboration and increased citations
- maximum visibility for your research: over 100M website views per year
At BMC, research is always in progress.
Learn more biomedcentral.com/submissions

